\title{
A trajectory for technology-supported elderly care work
}

\author{
Anita Woll1, Tone Bratteteig2 \\ 1 Department of Informatics, University of Oslo, Gaustadalleèn 23B, 0373 Oslo, Norway (E- \\ mail: anitwo@ifi.uio.no, Phone: +47 91543736) \\ 2 Department of Informatics, University of Oslo, Gaustadalleèn 23B, 0373 Oslo, Norway (E- \\ mail: tone@ifi.uio.no, Phone: +47 22852427)
}

\begin{abstract}
To enable elderly people to live independently in their homes, the government aims to de-institutionalize elderly care services by upscaling home care services and care housing and downscaling long-term stays at nursing homes. Increasing use of assistive technologies will play a significant role in the ongoing transformation of care services, however our empirical data shows how difficult appropriation and use of technology are for elderly endusers. In this paper, we suggest a comprehensive elderly care trajectory model that includes the collaborative work of self-care, formal care, informal care and technology. We build our trajectory on empirical studies of elderly people using assistive technology in a care housing and in nursing homes, in addition to Corbin and Strauss' classic work. Our proposal of an elderly care trajectory fits with the municipal care staircase, but challenges its minimalist service level focus, as well as its late and limited introduction of technology.
\end{abstract}

Keywords: elderly care, trajectory, healthcare services, assistive technology

\section{Introduction}

The growing elderly population challenges the current organization of elderly care services and calls for new ways of delivering care work in a more cost-efficient manner (Norwegian Directorate of Health, 2012). The public health authorities stress that the amount of formal and institutionalized care services cannot maintain over time without compromising the welfare society. Thus, the elderly care arrangements must transform into more sustainable delivery of services involving to a larger degree work such as self-care and informal care. To accomplish this shift in elderly care work, the governments have developed several strategies including active aging, new types of housing supporting independent living, increased use of home-based care services and expanded use of assistive technologies.

The notion of "active aging" addresses that aging itself is not a disease, even if aging increases the risk for diseases and mortality (Harman, 1991). Active aging fits with trends in global health policies aimed at developing strategies for successful aging and differs from traditional welfare state policies that the state takes care of its old citizens if they need care. Today, the citizens and their informal care providers (families and friends) will have to take the main responsibility for the citizens' health. The notion of 
"successful aging" addresses aging as positive physical, mental and social well-being in old age (Rowe and Kahn, 1997; Katz, 2013). Studies also show that elderly people's subjective experience of quality of life is more important than just absence of diseases (Rowe and Kahn, 1997; Fries, 2002). The notion of successful aging aims to develop strategies for increased adaption of a healthy lifestyle in the population (Jeste et al., 2010; Katz, 2013; Hamblin, 2010). Elderly people with none or minor needs for care services are therefore important resources in the transformation of the elderly care practice.

Most elderly people want to live independently in their homes as long as possible, and the majority of elderly people (74\%) are actually doing so by the support they get from their family, see Figure 1. Over the two last decades, housing-oriented care such as assistive housing has become an international trend (Daatland and Otnes, 2014), but is still viewed as controversial in Norway. Assistive housing includes nursing homes and care homes, whereas the governments' aim is to upscale care homes, downscale long-term stays in nursing homes, and to develop more extensive and robust home care services to provide increased home-based services (Daatland and Otnes, 2014). The increased use of technologysupported care also plays a significant role in the transformation of elderly care services. However, in Norway, the use of assistive technology has been relative limited in scale, and has been mostly concerned the use of a personal safety alarm.

In this paper, we first address the role that technology plays - and can play - in self-care activities, as well as, in formal and informal care services. In doing so, we explore how technology can be better incorporated into private homes of elderly people and support them in transitions to assistive housing offered as part of elderly care. The increased emphasis on self-care activities implies that some of the current care work arrangements are delegated from healthcare professionals back to the patients/citizens themselves (Woll 2016a, 2017), or to their informal care providers, e.g., by the introduction of the digital medicine dispensers. Moreover, some parts of the care work are delegated solely to technology, such as the wash-and-dry toilets. Secondly, we position self-care in the larger context of the government's handling of the growing elderly population, and discuss the balance of self-care activities, formal and informal care services by proposing a conceptual elderly care trajectory. This paper adds to the existing body of knowledge about how technology can support elderly people with unstable user needs because of increased health issues. There is a lack of CSCW research discussing the balance of self-care, formal care and informal care as a collaborative work effort to develop more efficient care arrangements.

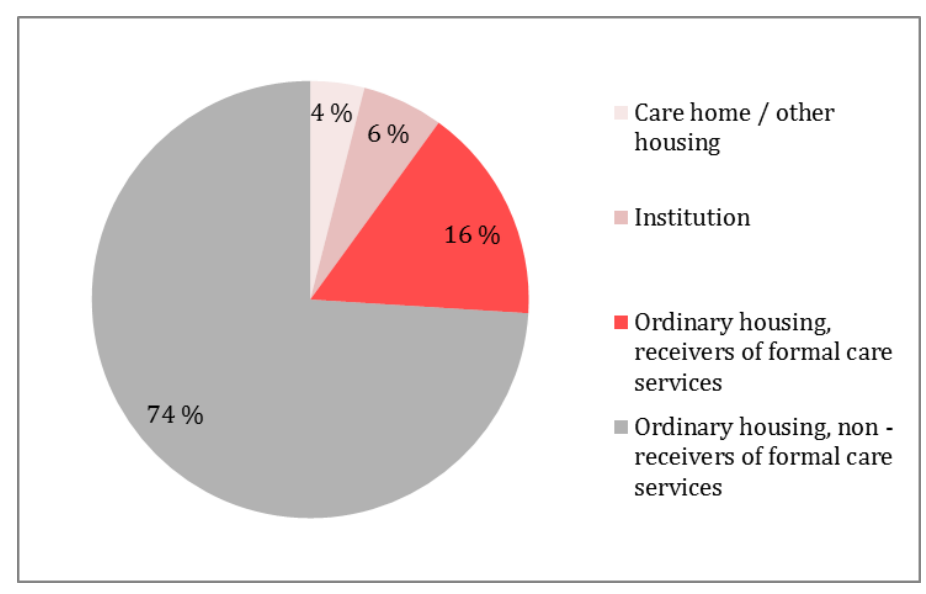

Figure 1. Housing arrangement for elderly Norwegians as from 67 years of age (Statistic Norway, 2013). 
The paper is organized as follows. Section 2 presents the municipality's elderly care staircase, which gives an overview of the current formal healthcare services offered to elderly care receivers in Oslo. Section 3 describes several types of assistive technologies, and the importance of separating between active and passive use of technologies. Section 4 presents related research. Section 5 describes our findings from empirical studies of elderly people and their mastery of technology in practice; a fieldwork done in a care housing with additional user needs assessment in four nursing homes. In section 6, we analyze our empirical material using Strauss and Corbin's illness trajectory model, and identify an overarching ageing trajectory that comprises self-care as well as informal and formal care. Additionally, we address support during transitions between the trajectory phases. Section 7 discusses how technology can better support people as the trajectory is traversed, and emphasizes how elderly people can make use of technological support in time for them to prolong their habits and preferred ways of living. Finally, section 8 concludes the paper.

\section{The current organization of elderly care}

In Norway, healthcare and social services for elderly people are important parts of the welfare policy. The municipal healthcare and social services offered form a care staircase which differentiates the level of care and services connected to private homes, care homes, and nursing homes (NAKU, 2016), see Figure 2. The services are offered according to a principle of the lowest, effective level of care (Woll, 2017); the elderly person is assigned with sufficient services, but no more than necessary. There is little research on how elderly care receivers traverse the municipal care staircase. We also lack knowledge about the time spent in each housing arrangement during people's life (Daatland and Otnes, 2014). The ideal way of traversing the staircase is step-by-step from the beginning (in the original home) to the "top" by expanding the set of services as the person's needs for care increases.

Elderly home-dwellers and/or their relatives must make a formal application and enclose a physician's statement and a medical certificate to document their needs to formal services. When the application office registers a new applicant, the local home care office makes a home visit to assess the applicant's needs and housing situation. Based on the physician's statement, the assessment made by the home care staff and oral information from the applicant, the application office makes a formal decision about the applicant's needs for e.g., a personal safety alarm, food delivery, practical assistance, short-term stays and home care services etc. All applications are evaluated individually, and decisions are formally made based on the applicant's cognitive and functional ability and housing situation.

Elderly persons feeling unsafe in their own homes can apply for a short-term stay or long-term stay at a care housing. An application for care housing is assessed according to a set of criteria based on formal regulation for allocation of care homes (Formal law regulation, 2011). For example, applicants must be over 67 years and have a medical certificate of prolonged disability. Prospective residents are also expected to master independent living and have the capacity to partake in, and benefit from, the inhouse services. However, elderly people living in ordinary homes needing home care services can apply in an equivalent manner. In Norway, receivers of homecare services pay a reduced amount for homecare services per month. There are exceptions like visiting a senior center or a short term stay at safety departments, which are free services, and therefore, low threshold services accessible for all elderly people. 


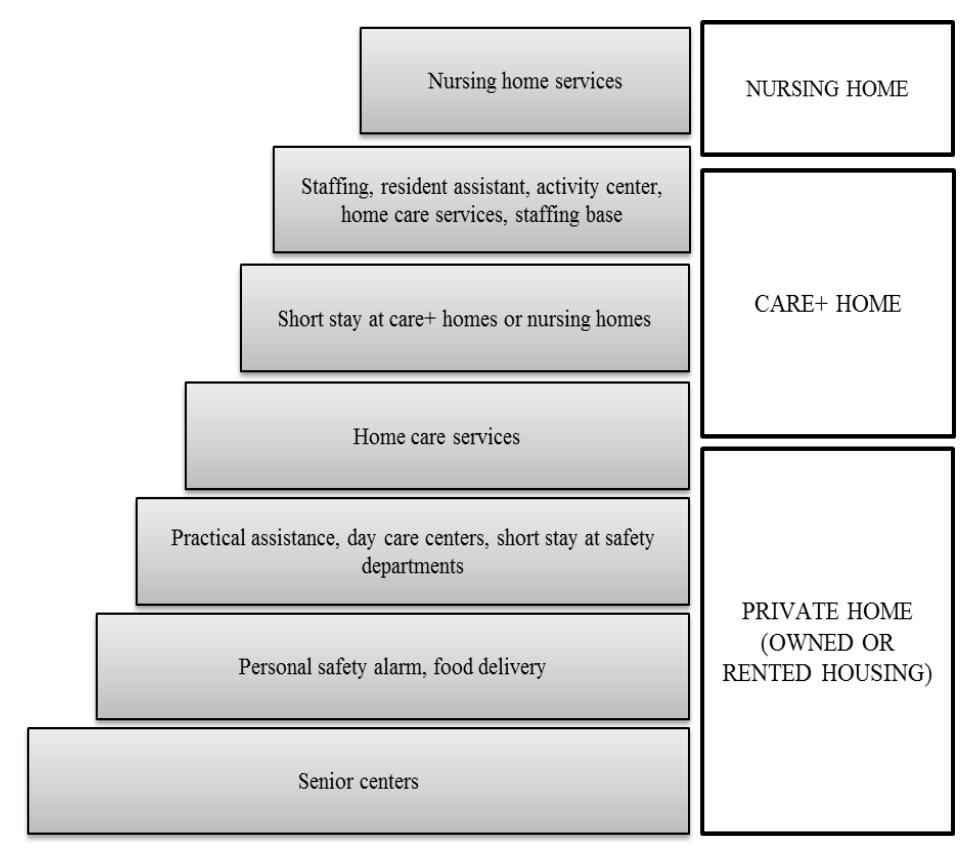

Figure 2. The care staircase illustrating municipal elderly care services (formal care).

Evaluations of applications for short or long-term stays in nursing homes are based on the applicant's functional ability and current care situation: on where in the care staircase he or she is placed. Those who are on short-term stays in nursing homes are often highly motivated to return to their ordinary homes, unless they are under assessment for long-term stays or are under terminal care. Those who are granted a long-term stay in a nursing home are assessed as a person with extensive and complex care needs that cannot be met by the offerings of care housing and/or home care services. A long-term stay in nursing home is a permanent residence with around the clock inpatient care. Stays in a nursing home are expensive for both the municipalities and the resident. The prohibitive cost is associated with the $24 / 7$ staffing. The maximum payment for a long-term stay is $75 \%$ of the social security payment. However, if the residents have additional assets the municipality can also claim up to $85 \%$ of these savings.

Although most elderly Norwegians are self-dependent after retirement (74\%) (Statistics Norway, 2013), many elderly people use healthcare services during their final years of life, especially for the end of life care (Gabrielsen, 2013). In 2014, Daatland and Otnes reported that $68 \%$ of elderly people (aged 80 years or over) died in nursing homes, $8 \%$ died in sheltered housing, and $20 \%$ of elderly people who died were receiving one or more "other services". This means that $96 \%$ of elderly people (aged 80 years and over) who received the services available in the care staircase did so during their end of life care (Daatland and Otnes, 2014). Thus, dying has become the responsibility of the formal healthcare service providers. Consequently, it is argued (e.g., in the Senior Report (2014)) that people receiving end of life care should be "taken back" to their homes, as was the case years ago so that they may die in peace, in a familiar environment together with their closest family and friends.

\section{Assistive technologies}

The notion of assistive technology, which in Norway is termed "welfare technology", is an umbrella term for user-oriented technologies aiming to provide or assist users with public or private welfare services. Welfare technology is defined in a wide sense as technologies that supports the citizen to 
participate in the society. These services can be technical support of the users' safety and security, daily life activities, self-reliance, and participation in activities (NOU 2011, 2013). Welfare technology is divided into four main categories of technology support: for 1) safety and security, e.g., the safety alarm service, 2) compensation and wellness, e.g., memory support, walker, light/heating control, 3) social contact, e.g., video communication, and 4) care and treatment, e.g., blood glucose meter, blood pressure monitor (NOU, 2011). The technologies are aimed at enhancing weakened abilities of a person (like glasses, arm-grasping forceps) or replacing lost abilities (like wheel chair, hearing aid).

When healthcare services move into the home they are often accompanied by tools and technologies aimed at supporting "independent living". Tools and technologies are delegated tasks previously done by humans, like the traditional manually medication dispenser, or the recent digital medication dispenser that reminds the user as well as her/his care providers. Bratteteig and Wagner (2013) emphasize that there is "work to make home care work" (p.145) - and that modern technologies need care and adjustment from both care receivers and care providers. Home care technologies change the caretaking in the home, and affect the relationships between the care receiver, informal providers (family members, friends and neighbors) and the larger network of professional care providers (practical support, professional home care services and care centers etc.) (Woll and Bratteteig, 2017). This view fits with our emphasis on seeing the elderly care in a larger context and over time, and this is our basis for suggesting an "elderly-centered" way of organizing elderly care.

We find it useful to distinguish between active and passive use of technologies, pointing to the fact that technologies can be designed with various levels of automation in order to support a diversity of users with different functional disabilities ranging from minor to severe disabilities (see e.g., Ministry of Education and Research, 2011). We argue elsewhere that also fully automated technology can give users full autonomy, and there is no one-to-one relationship between the level of automation and the user's autonomy (Woll and Bratteteig, 2017).

Conscious and active use of technology refers to situations when a person interacts with technology for a purpose, like doing a blood glucose check or pushing the personal safety alarm button when in need for assistance. This requires that the user is familiar with the technology's function, and knows how to perform the necessary steps and accurately operate it. Active use is different from passive use of technology, where the technology does not require any conscious input by the user, e.g., an alarm is triggered automatically when pre-set conditions are met. For example, a fall sensor can alert people for assistance on behalf of the user when detecting a user on the floor. In such cases the user interacts with the technology without being aware of its interaction mechanism. Other examples of passive use of technology include shower nozzles / water faucets that provide constant temperature in the bathing / shower water, infrared water tap flow control, or automatic refrigerator door closer to mention a few (Mao et al., 2014).

Passive use of technology is particularly interesting for users who cannot be expected to understand abstract or symbolic representations (Woll and Bratteteig, 2017). For example, nursing homes with old residents ("the oldest old") often have a high prevalence of dementia, suggesting a higher level of automation and passive use for the technology to support the users. Persons that are affected of cognitive impairment are likely to struggle in situations where active use of technology is required. For instance, in the situation where a person with cognitive impairment falls on the floor, $\mathrm{s} /$ he may not understand that $\mathrm{s} /$ he has the possibility to alert people for help by actively pushing the personal safety alarm button. Thus, users with stated cognitive impairments and increased healthcare challenges need to be offered alternatives to active use of technology. Another user issue is that elderly people sometime choose not 
to call for assistance as they do not want to be a burden; "Seniors in general don't ask for help because they think they will inconvenience the health personnel" (Bowes and McColgan, 2012).

Passive use of technology is not merely for residents in nursing homes. Most elderly people suffering from dementia live in private homes or care housing. Thus, implementation of various sensor technologies can support them by increasing their safety and security with respect to preventing fire, preventing or alerting falls, or alerting if they wander outdoors during night.

\section{Related research}

Relatively few CSCW studies on healthcare have focused on the introduction of assistive technology within the homes of elderly people, or the use of such technology in care housing or nursing homes; however, some studies do exist. Proctor et al. (2016) have studied the work arrangements of the telecare call center staff, who act like the response unit for calls and alarms to support elderly people to prolong their ability to live in the home. The authors state that there is a gap in the political ambitions for the use of assisted living technologies and the use of such technologies among elderly people in practice. Moreover, the authors pinpoint the lack of match between the elderly people's need for daily life support, and the technologies that are provided to support them. However, even if "care at a distance" has received critique for being impersonal and reducing social face-to-face contact, the authors report that call center staff acts as the "glue" (p. 79) in the network of care providers by "providing the allimportant link between otherwise fragmented services" (p. 79). Farshchian et al. (2017) address how the operators in a modern telecare call center use ICT tools to deliver care to users. They refer to Roberts and Mort (2009) stating that "[t]elecare systems introduce a paradox in that they introduce scale and a new form of distance into home care work, whilst simultaneously making care appear more immediate" (ibid, p.142).

Aaløkke Ballegaard et al. (2006) conducted a research project into assisted living on the use of a tablet for access to home-based services targeting elderly people. They argue that the technology should merge with the changing functional abilities of older people. Moreover, they criticize the fact that assistive technologies often are introduced to follow-up a sudden decline of health, in so-called acute phases of older people's lives. They recommend instead to introduce the technology before the acute phases to prevent acute situations. Moreover, the authors address the challenge of designing healthcare technology "which will be able to fit into the everyday life of the citizen." (p. 1808). They argue that healthcare technologies should be an integrated part of the home environment, and not necessarily being visible as something that could stigmatize the resident by displaying that $\mathrm{s} / \mathrm{he}$ has healthcare equipment in the home.

Much of the current literature on assistive technology pays attention to technology-supported followup services after hospitalization, especially concerned the patient transition from hospital and back home (Grönvall and Kyng, 2012; Korhonen et al., 2003; Milligan et al., 2011; Aarhus et al., 2009; Grönvall and Verdezoto, 2013).

Aarhus and Aaløkke Ballegaard (2010) provide a distinction between being a patient in the hospital versus in the home, also concerning the use of technology. They refer to their informants, who express that hospitalization allows one to "concentrate on being sick" (p. 1230), in contrary to staying home, where the focus is not solely on the disease management, but also on daily practical and social arrangements including handling different family roles. The authors state that "at a hospital there is somebody to take care of the patient and to receive help from, while patients at home are more on their 
own" (p. 1230). In the hospital, the patients are often "just patients", but in the home, the person represents various roles, in addition to managing the disease(s). Thus, in the home the person is "more" than just the disease, while in the hospital the patient role is represented by the disease. In care situations, where the residents are receiving follow-up services after hospitalization, the home becomes a place for both public and private matters, in which many informants are reported to hide healthcare technologies.

The focus on technology-supported out-patients returning home remain narrow in dealing merely with follow-up services after hospital admission, consequently, they do not bring attention to technology supporting people as part of the elderly care practice. These users can experience shifting needs over time. There is little CSCW research on technology support for the transfer from short-term stay at care housing and nursing home, to the return home. Moreover, research on the move from private home to care housing and/or nursing homes and technology-supported services for the users in various phases during the elderly care is lacking.

Fitzpatrick and Ellingsen (2013) see the introduction of technology into the home as a "movement towards technology-enabled care at home with a greater focus on self-care." (p. 637). They state that the exploration of such technology for monitoring or self-care can indicate a drift towards reduced human healthcare resources being physically present in the home, as well as an increased focus on the users and their experience of well-being and comfort. Hofmann (2013) argues further that "[m]any kinds of welfare technology break with the traditional organization of healthcare. It introduces technology in new areas, such as in private homes, and it provides new functions, e.g., offering social stimuli and entertainment. At the same time welfare technology is developed for groups that traditionally have not been extensive technology users." (p. 389). Furthermore, Hofmann raises concerns about the ethical implications of such development of healthcare services, saying that "[i]f advanced health technology spreads from hospitals to private homes, the challenges recognized in hospitals will spread to the home: withdrawal of treatment, autonomy to refuse treatment, advance directive" (p. 398).

According to Fitzpatrick and Ellingsen (2013), CSCW studies about cooperative work arrangements in healthcare settings mainly focus on exploring place and time issues in work practices of healthcare professionals (e.g., Wagner, 1993) or the coordination of these cooperative work arrangements (Bossen et al., 2013; Bardram, 2000; Berg, 1999). CSCW research studies put emphasis on coordinated work as a basis for designing situated computer systems that support and organize work, including computer support for healthcare professionals with partly unpredictable workflow (Fitzpatrick and Ellingsen, 2013). One of the few CSCW contributions concerned with home care work is by Nilsson and Hertzum (2005). They have studied the role of rhythms in the collaborative coordination of mobile work. Their focus concerns time, place, and work schedules and they analyze the "collaborative rhythms of a tightly regulated work setting characterized by local mobility" (p. 156). Also, Pinelle and Gutwin $(2002,2003)$ have looked at the collaborative nature of home care workers and point out that "home care collaboration is limited by several characteristics of the setting, including the mobility of clinicians, schedule variability between team members, and the rarity of face-to-face meetings between team members.” (p. 621).

Pinelle and Gutwin (2003) analyze the mobile work of home care workers as a "loosely coupled collaboration style" (p. 75) They argue that "since collaboration and interdependencies are minimized, workers usually have the flexibility to deal with the unpredictability of the work setting without consulting others" (p. 83). Petrakow (2007) examined the design and development of a healthcare information tool by use of a binder to support both cooperation and coordination of elderly care services 
in the home. She reports the functions of the existing paper-based SVOP binder $^{1}$, and further makes suggestions regarding an IT tool that could compensate for the restrictions of the paper-based binder system. In her study, Petrakow argues that home care work is more complex than hospital work, the reason being that work activities in the home take place in a context that is difficult to change. These work activities must be coordinated, not only, between the various care providers within one organization, but also between different organizations, because a person's care network is often fragmented, consisting of many different care providers. She argues that the care work needs to be coordinated between the various workers, who are in separate places and work in shifts. She emphasizes the importance of the binder supporting the patient centric view, which is complementary to the clinicalcentric view presented by Fitzpatrick (2004). Amsha and Lewkowicz (2016) build on the concept of knotworking2 proposed by Engeström et al. (1999) to better understand self-employed health and care professionals promoting a collaborative approach to home care services in France. Like Petrakow (2007) they acknowledge the need for a coordinative artifact such as a notebook for sharing information and coordinating the care work. Together these studies provide important insights into the work of home care staff, however, these contributions do not pay attention to the care receiver as an essential partaker of the collaborative care work. Grönvall and Lundberg (2011) present an interesting analysis of the complexity of introducing technology into the homes of care receivers as seven challenges concerned with implementing pervasive healthcare solutions in private homes. They argue that these challenges go beyond application specific considerations, e.g., choosing the "right" sensor or developing an intuitive user-friendly interface. One (of several) relevant challenges to this paper, is "appropriation", which they understand as aspects related to how technology becomes part of people's everyday lives whereas "new technology must be interpreted and ascribed meaning" (p. 28). The authors stress that appropriation is time-consuming, an on-going process, and "it is through a dialogue between the user and a contextualized artifact that appropriation takes place" (p.28). They bring awareness to the fact that introduction of healthcare technologies is appropriated in varying degrees into the users existing routines and daily lives. For additional studies of the coordination and home care work, see Joshi and Woll (2014, 2015a, 2015b) and Woll (2016a, 2017).

There are several studies looking at the use of a particular welfare technology. Some research projects are aimed at supporting medication administration in the homes of elderly people (Siek et al., 2011; Dalsgaard et al., 2013). Furthermore, there are studies into: how elderly people deal with interactive interfaces (Culen and Bratteteig, 2013; Haikio et al., 2007), how elderly people use modern technology (Heart and Kalderon, 2011), applications for social participation (Alaoui et al., 2012; Dewsbury et al., 2007), and self-monitoring and home technologies for rehabilitation (Grönvoll and Verdezoto, 2013; Axelrod et al., 2009). Several studies concern how remote care technologies change the home context and the conventional care work practices (Milligan et al., 2015). In their discussions about the move of healthcare into the home, Bratteteig and Wagner (2013) explore how homecare technologies change

\footnotetext{
${ }^{1}$ SVOP binder is in practise a tool for cooperation and coordination of the care work in the home (Petrakow, 2007). The tool is used to support home care workers to better be able to cooperate and coordinate their efforts during the care process by access to accurate information and communication. Thus, the SVOP binder is a shared information space for the network of various care providers.

${ }^{2}$ The concept of knotworking, also referred to as the knotworking model developed by Engeström et al. (1999) is applied to understand contexts that are "boundary-crossing, collective problem-solving way of organizing work" (p.322). In a speech at IFLA 2012 Yrjö Engeström talked about the concept of knotworking where he refers to this concept as a "space" where distinct actors can get together and "tie a knot" collaborating on a problem that needs to be solved rapidly and efficient. The model is relative complex so a brief description of the model in a footnote is not giving the concept justice.
} 
how caretaking in the home is carried out, turning the home into a workplace for professional caregiving. They recognize the many different kinds of work that care receivers and providers do by building on the research of Corbin and Strauss (1991). However, there is little CSCW research that has explored how technology can support the various types of elderly care work. There is also a lack of research discussing the balance or mix of self-care, formal care and informal care, or how these collaborative work resources can develop into new care arrangements by the support of assistive technologies.

\section{The use of assistive technology in practice}

This paper builds on studies of the use of assistive technology in the setting of assistive housing as part of the formal care staircase. In this section, we present fieldwork from two case studies. The initial case study focused on assistive technology practice in a care housing in a part of the old town of Oslo, Norway. The second case study concerned user assessments of assistive technologies in nursing homes. We also include findings from a two-year action research study carried out together with home care service office in the same district as the care housing.

\subsection{Use of assistive technology in care housing}

The municipality of Oslo gave us the opportunity of studying the use of smart home and welfare technologies that was installed in a new care housing. The housing has 91 apartments. One of the apartments was a demo-apartment, which the municipality gave us (researchers) access to in order to carry out practical research studies. We used the apartment for usability testing of a telecare set-up as part of the action research study (see section 5.2). The building has a reception desk and staffing 24/7, a common area for meeting people, an activity center for elderly people, a daily cafeteria selling dinner and cookies, a gym and a library with Internet access. The staff organizes activities for the elderly residents, like computer classes, quiz, music concerts and gym gatherings, and the common area is popular among the residents for unformal meetings and coffee breaks with companions. The staff does not provide healthcare services, merely practical support; thus, the residents who need such services must apply to the municipal home care services similar other home-dwellers. Several of the residents have moved from old and inconvenient housing, thus, the aim with care housing is that such a tailored home environment can increase the residents' independency and autonomy. The residents get access to nutritious meals from the cafeteria and often they eat dinner together. The ease with which they get and maintain social contact is an important element for counteracting age-related decline.

The apartments were installed with smart home technologies (energy saving lighting, stove alarm, water lock), a tablet and a personal safety alarm. The tablet has a local in-house application giving users access to in-house services including today's menu in the café, dinner order from the café, overview and registration for social events, calendar, photo album, web-TV and online newspapers. The calendar can also be shared with remote users (e.g., by the physiotherapist, hairdresser or relatives).

In this setting, we carried out fieldwork as part of a case study of the residents' use of welfare technology. The fieldwork started before the technical implementation in December 2012 and lasted for 2 years. As the housing became increasingly operational and the users were able to interact with the technical solutions installed, we experienced that the well-known and established technology failed, thus, we started to systematically look for problems (Woll, 2013). The many sensors and alarms did often not work as planned, e.g., the bathroom lighting was turned off when the residents used the shower 
curtain while showering because then the sensor did not capture any movement. Most residents hesitated to use the tablet from the beginning. The fact that the vendor who delivered the application running on the tablet platform had a high frequency of software releases, resulting in a "dead screen" on the tablet, dis-encouraged many of them even more. However, the most eager users reported to find the tablet useful for looking up today's dinner menu, getting an overview of the in-house activities, or reading newspapers. However, for most of the residents the modern technology was introduced too late in the sense that they had problems learning to use the, for most of them, unfamiliar technology.

Several residents in the housing were able to self-care with the support they got from the in-house staff, their relatives and the home care services. However, during our fieldwork we learned that many residents experienced increased health problems over time requiring more home care support. Moreover, those with the most need for care were given priority in the morning (e.g., to get help to get out of the bed), so residents with minor health issues expressed that they felt ignored and left waiting for the home care staff to arrive for their visit. One of the residents stopped receiving home care services because the staff never arrived at the same time on any one day and he simply could not cope with having to wait for them all day (even if he needed follow-up services after a temporary hospital admission). Another resident had concerns about the number of different nurses that came into her private home, which she found uncomfortable and intrusive. Thus, to address user issues concerned with active aging residents not being able to start their day early on, we initiated an action research study together with the district's home care service, aimed at using telecare as a means for delivering selected home care services.

\subsection{Use of assistive technology as a means for delivery of home care services}

During the action research study, we tested if the television set could be used as the platform for telecare sessions for timely and accurate delivery of home care services. We built the choice of technology on recommendations made from other researchers: 1 ) to use technology that fits into the elderly persons' daily life activities (Aaløkke Ballegaard et al., 2008), 2) to build on familiar and existing technology in the home to avoid stigma (Aaløkke Ballegaard et al., 2006), 3) to start with the use of ICT before acute illness (Aaløkke Ballegaard et al., 2006), and 4) to mobilize physical visits in cases of uncertainty (Roberts et al., 2012, p.10). The study was done together with the home care service staff in a part of the old town in Oslo. The home care services are put under excessive pressure to organize services in a more cost-effective manner to more elderly people with same or reduced staffing, thus, they were positive in testing technologies to develop their services into potentially more sustainable ones. The television as the platform for telecare was a natural choice as we wanted a technology with fixed power supply to avoid re-charging any battery, which many elderly people find troublesome. All the residents at the housing had large television screens, see figure 3. By adding a wide-angle HD camera, we were able to capture both the living room and participants sitting in the television-chair - to see more than just their faces - as the state of a home can give additional information about a person's well-being. We also observed that the fixed position of the television screen and the camera within the living room were helpful to compensate for any decline in participants' motoric skills (Joshi and Woll, 2014). The television set represented a familiar technology, which the participants found understandable and easy to operate. However, when we moved the study from a controlled environment (the demo-apartment) into the real life of the participants (their private homes) we achieved broader insights into the elderly care receivers' challenges of implementing modern technology into their everyday life routines (Woll and Joshi, 2015a). For example, over time the benefits of a stationary user interface in a fixed position were not flexible enough to handle situations when the participants were unexpected bedridden or 
bedridden for periods because of acute illness. Therefore, bedridden participants had to get traditional home care visits: they were not able to operate telecare sessions as the amount of "background work" or self-care abilities were decreased for a shorter or longer period. However, most of the participants recovered after some time and were able to return to receive home telecare sessions. This indicate that the balance of self-care and traditional formal care can vary over time, but that the balance goes both ways, and that people can recover and take up their self-care abilities.

We also tested the tablet as a platform for telecare. However, we observed that it was difficult for the residents to hold the tablet high enough for the telecare caller to actually see the participant's face. The tablet was experienced as heavy for those with reduced lifting capacity. In addition, the tablet had to be put down on the table when the resident was to carry out a task with her/his hands (e.g., take medication). Furthermore, the elderly participants often forgot to bring along their tablet with them when moving from place to place in the apartment, so in practical use, the tablet was experienced as just as stationary as the television.
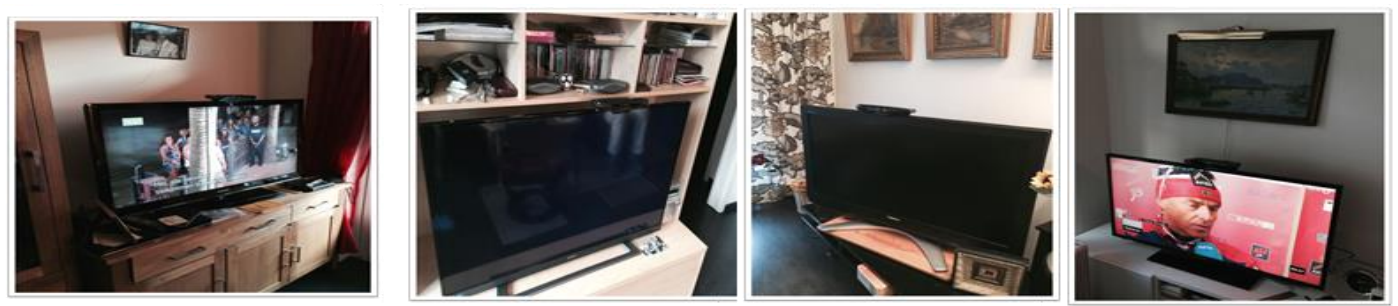

Figure 3. Televisions in the private homes that were used for remote home care services during the change experiment. (Joshi and Woll, 2015b).

We applied several methods during the action research cycle; see Figure 4, which presents an overview of the applied methods, number of participants and the collected data (see Joshi and Woll, 2015b for detailed information about this study).

\begin{tabular}{|c|c|c|c|c|}
\hline$\#$ & Method & $N$ & Collected data & Inquiry method \\
\hline A & Preliminary field studies & 15 & Photographs, field notes, interview data & Home visit, unstructured interviews \\
\hline B & Task elicitation workshop & 11 & Field notes, problem grading & Open discussion \\
\hline $\mathrm{C}$ & Usability testing & 8 & Photographs, usability grading, video & $\begin{array}{l}\text { Two-sided observation, usability } \\
\text { assessment, statistical analysis }\end{array}$ \\
\hline D & Diagnostic evaluation & 34 & Diagnostic grading, photographs, field notes & $\begin{array}{l}\text { Post-interview, usability assessment, } \\
\text { two-sided observation, questionnaire }\end{array}$ \\
\hline E & Post-experimental workshop & 6 & Field notes, photographs & $\begin{array}{l}\text { Categorical labeling, open-ended } \\
\text { questions }\end{array}$ \\
\hline $\mathrm{F}$ & Case study & 4 & Photographs, field notes, usability grading & $\begin{array}{l}\text { Post-interview, questionnaire and } \\
\text { observation }\end{array}$ \\
\hline
\end{tabular}

Figure 4. Overview of methods applied in the action research study (Joshi and Woll, 2015b).

A central finding from this study was the many context-dependent user issues appearing when moving the home telecare solution from the demo apartment into the private homes of the elderly participants. This finding is very important for the potential to actively use welfare technologies as part of the care delivery. The use of home telecare was highly affected by the users' context, and less concerned about their technical capabilities. The timing of the telecare call had also influence on the user's ability to incorporate ICT-supported care into their daily life activities. The timing was complicated; the participants had all agreed upon a suitable time for their call, so the timing problems seem less concerned about the time of the call than the unpredictability of the daily life activities that interfered with and prevented the participants from taking the call. We experienced that participants were unable 
to take the telecare call because they stayed in bed on "a bad day" with an unplanned set-back of the health condition, or they were eating breakfast and were unable to move from the kitchen area to the living room (in time) because of mobility issues, or they were absent from the home at the time the video consultation was supposed to take place. If they were not ready, in the sense that they were sitting in the television chair, they did not answer the call. They also experienced the television as complex to operate when additional devices to the platform were introduced. For example, to receive telecare calls they had to change the HDMI source from the set-up box to the camera, and afterwards back again to watch television - which was an operation that all participants struggled with and found difficult to learn.

Telecare use is also vulnerable due to lack of control of the infrastructure, e.g., the network capacity in the private spaces and the camera connection to the television set. Moreover, home telecare such as video-conference requires a certain degree of functional capabilities and stable health condition to be experienced as appropriate and useful for the elderly participants. We also experienced several occasions where we had to make a home visit or delay our call-in order for the participants to be ready for home telecare sessions. Additionally, the participants' health conditions got worse as the study unfolded. A decline in health conditions is a reality for elderly people, and the changing user capabilities need to be considered when designing technical solutions for elderly care receivers. Thus, to maintain telecare over time for these users, it would be a necessity to add redundant solutions such as passive use of technology (e.g., sensors logging 24/7) as backup to also support them during the days where they were not able to carry out telecare sessions. Lessons learned and transferable to the design of an elderly care model are that replacing a physical visit with a digital visit to get a glimpse of the care receivers conditions at a set time during the day is not a sufficient support. There is a need for expanded use of technology around the clock in addition to the telecare solution to capture deviation from the care receiver's regular everyday life activities. This to reduce all the extra work experienced during the action research study because of not knowing the state of the user situation in cases where the participant did not immediately respond to the telecare call.

\subsection{Use of assistive technology in nursing homes}

As we learned how challenging the active use of technology was for elderly participants as part of the action research study, we became curious about how residents in nursing home were able to appropriate the use of technology. Thus, we initiated a case study of the residents' use of welfare technology in nursing home. Residents in nursing homes have expansive healthcare needs, they are the oldest old, and most residents have cognitive impairment. It is reported that approx. $80 \%$ of the residents in nursing homes have cognitive issues such as dementia. The first author therefore visited the current forefront in nursing home design to interview the staff at the municipality of Skien. Among other, it was experienced that the residents had little use of the personal safety alarm, as most of the residents with cognitive impairment did not understand how to use it. To compensate for the lack of mastery of the personal safety alarm, the nursing home had installed sensors like door detectors to prevent the residents from wandering outside during night thinly dressed; this is particularly dangerous during winter. We have read about elderly people being lost and sometime sadly found frozen to death outdoors. Therefore, preventive measures such as door detectors are important in elderly care. During the user needs assessments with four nursing homes, the nurses reported that only $30 \%$ of their residents were able to use the personal safety alarm. Hence, the nurses state that in practice most of their users are unable to understand how the safety alarm works when an accident happens, and assistance is needed. This makes alternative and redundant solutions necessary for supporting the safety of users who are unable to 
operate the alarm. Newer nurse call systems have therefore added diverse types of sensors (e.g., fall sensor, camera for tracking absence from bed, epilepsy sensors) and controllers (e.g., door controller) to the nurse call systems for passive use of technology. The person-centered care philosophy also advocates a need for making nursing homes more home like and less institutional. This has resulted in so-called silent nurse call systems where alarms go directly to the nurses' mobile devices, instead of noisy alarm sounds and blinking corridor displays.

The increased passive use of technology seen in nursing homes should preferably be integrated into the technology-supported private homes and care homes, to support elderly people in risk for sudden decline or rapidly shifting health issues that limit their capacities for actively operate technologies such as the personal safety alarm.

\section{Applying the concept of trajectory}

To arrive at a more seamless elderly care package when providing healthcare services for elderly people, we have applied the trajectory concept suggested by Strauss and colleagues (Corbin and Strauss, 1991; Strauss et al., 1985). Corbin and Strauss (1991) describe a trajectory as the illness or chronic condition path that evolves and is formed by collaborative work made by the individual (self-care), his/her family (informal care) and healthcare providers (formal care). Corbin and Strauss (1991) and Strauss et al. (1985) refer to trajectory work as the management of a patient trajectory through distinct types of work required for serving the trajectory, and the inter-relationships between the various actors involved in this work. They also acknowledge the patients' work during hospitalization, and characterize this work as invisible work, since the patients' contributions during hospital stays are normally not considered work by the healthcare providers (Strauss et al., 1985). Moreover, Strauss and co-authors emphasize that care work is "people work" and is an essential aspect of the healthcare work (Strauss et al., 1985). They argue that unless the patient is unconscious or completely disabled, the patient can influence the care work. In addition, the patient can join collaborative care activities and become a care worker her/himself. For the patients to better handle their trajectory work, Strauss et al. suggest that they are supported with the necessary technology. In this context, technology refers to any assistive support and can range from walkers to fully automated services. In this paper, the self-care work of elderly people is also recognized as "trajectory work" (Strauss et al., 1982) including both invisible work and visible work. For example, in the action research study we experienced that the telecare session failed when the participant did not master to carry out the necessary "background work" ahead of the telecare session (see section 5.2). Strauss also stresses that chronically ill patients often are highly knowledgeable since they are "experienced" patients, and have been passively or actively involved in repeated procedures concerning their care and treatment. Strauss further addresses different patient's scenarios during hospitalization in which patients make contributions that should be recognized as patient work as follows:

- Expecting patients to work

- Demanding patients to work

- Inviting patients to work

- Negotiating patients to work

- Teaching patient to work 
Strauss concept of patient work is also transferable to the self-care work of elderly people living in ordinary homes or care homes. The movement towards active aging and the aim to not provide more services than necessary promotes increased self-care work among elderly people including all these sub-types of patient work listed above. In the past, care services were provided also to healthy elderly persons e.g., social visits ${ }^{3}$ and elderly people were often viewed as "needy" despite their health conditions. Today home care nurses are no longer providing merely social visits as the threshold for getting access to public care services have increased (Woll, 2017): most care receivers today have relatively complex needs for healthcare services so persons with minor care need must carry out selfcare or find support elsewhere e.g., from family or voluntary organizations. Elderly inhabitants are expected to be active aging and to take responsibility for their own well-being if having the capacity in doing so. Strauss and co-authors also discuss patient work during problematic trajectories and decisionmaking. During a transition in the elderly care trajectory, there is likely to be both minor and major decisions to be taken by the elderly persons and their family. Older persons and their family often put considerable effort into researching information regarding the formal services available, both technical and social services, rehabilitation and the prognosis of an illness. By introducing modern technology in a common information space to provide access to relevant and accurate information about the standard elderly care trajectory, the elderly people and their relatives are invited to handle their trajectory work better.

Our analysis of the data collected during the fieldwork made us see the elderly person's "journey" as a trajectory where $\mathrm{s} / \mathrm{he}$ goes through many phases where $\mathrm{s} / \mathrm{he}$ needs increased levels of services. Like Strauss et al. (Corbin and Strauss, 1991) the "elderly care trajectory" starts with an incident: a fall, accident, illness, etc. that restricts a person's cognitive or physical capacity in doing everyday life activities for a shorter or longer period. A person may only need support until fully rehabilitated or may need permanent elderly care services. Our elderly care trajectory is inspired by the patient pathways suggested by Corbin and Strauss (1991): "Trajectory phasing represents the many different changes in status that a chronic condition can undergo over that course" (p. 162). Strauss and Corbin further divide each phase of the trajectory into three sub-phases (upward, downward, stable) but they also argue that sub-phases within a specific phase can span over a long-time period (e.g., as we saw in section 5.2 with the altering general conditions of the elderly participants of the action research study). The sub-phase concept points to the fact that the course of the trajectory varies, in sub-phases within each phase as well as in short-term and even daily variations.

Most elderly people experiencing illness have common characteristic symptoms: acute confusion, incontinence and inability to stand up and maintain balance (fall tendencies) (The Norwegian Medical Association, 2015). The prognosis of relatively harmless diseases such as a seasonal flu can be significantly worse for elderly people over 65 years of age because their immune system weakens with age (Center for diseases control and prevention, 2015). Other minor illnesses can also cause more severe effects for elderly people, for example urinary tract infections and constipation can lead to acute delirium (The Norwegian Medical Association, 2015). Falls are shown to be the eighth most frequent causes of death in Norway in 2013 (GBD, 2013). Hip fractures increase the risk of mortality and hip fracture patients over 80 years are especially vulnerable (Hektoen Faksvågen, 2014). The mortality is not directly linked to the fracture itself, but on the strains, that the fracture puts on elderly people's general health. Alzheimer' disease is the second most frequent cause of death in Norway (in 2013

\footnotetext{
${ }^{3}$ Today, voluntary organizations provide social visits to elderly people with minor or no need for public healthcare services.
} 
(Norwegian Institute of Public Health, 2015)). Alzheimer's disease is "not a normal part of aging" (Alzheimer's Association, 2015), however, the most dominant risk factor for the disease is aging. Most people suffering from Alzheimer's disease are more than 65 years of age (Alzheimer's Association, 2015), although $5 \%$ of those suffering from the disease experience symptoms already from the age of 40-50 years. Alzheimer's disease is divided into three stages according to the progress of the disease: mild (early-stage), moderate (middle-stage), and severe (late-stage). However, a person can experience that the symptoms and development of the stages of the disease varies. The changes in the brain related to Alzheimer's disease can last for several years before a person shows any signs of the disease, referred to as the preclinical period of Alzheimer's disease. It is difficult to categorize a person with Alzheimer's disease into a specific stage as the stages can overlap and progress differently.

A person's daily general condition is closely connected to his/her capacity of self-caring, and the need for care services can because of this, vary on a day-to-day basis. Therefore, aging is not a linear process: elderly people may experience shifting and unstable needs during the transitional phases. Neither is the development of dementia (or Alzheimer's disease) a linear process: when a person is sick or stressed, $\mathrm{s} / \mathrm{he}$ tends to be more forgetful - and the forgetfulness may disappear when $\mathrm{s} / \mathrm{he}$ gets well or relaxed. Hence, the transition between phases is unpredictable and the functional abilities must be assessed over time to change the patient's status to the next phase of the trajectory. Thus, the intermediate state between the phases: a "grey area" or a gap where the person may not fit either of the phases or rather fits into both to a varying degree, we call "transition". Transition through the elderly care trajectory is therefore understood as a process, and transfer is the physical process of moving from one location or housing to another. The terms transition and transfer are often interchanged in the literature. However, we find it important to distinguish these notions to provide appropriate services across the trajectory as it unfolds. The transition between phases can be unpredictable and the elderly person's functional abilities require assessment over time to evaluate the need for transfer to the next phase of the trajectory.

During our fieldwork (see sections 5.1-5.3), we observed that residents who actively used technologies, e.g., the tablet, the telecare solution and the personal safety alarm, also had unstable and shifting user needs depending on their illness or daily general conditions. We interpret this as a need to provide alternative arrangements by using different levels of automated services as back-up solutions to better support the unstable mix of self-care, formal care and informal care, on a daily basis.

\subsection{Identifying the trajectory phases}

In this sub-section, we present the analysis of our empirical material with the aim to create an overview of how the use of assistive technologies and the need for healthcare services can play together to better support elderly people in their daily lives. Our empirical material as the basis for the trajectory model design is grounded in the fieldwork presented in sections 5.1-5.3 and includes informants from the case studies of assistive technology use in a care housing and a nursing home, together with the action research study. In addition, we have informants living in ordinary homes. We have structured our analysis by incorporating the experience of our informants and their capacities for using technologies during the various steps in the traditional staircase, and we have added the care providers' perspectives on how to best address those needs. Furthermore, we have used Corbin and Strauss (1991)'s trajectory concept to design a conceptual elderly care pathway.

The care housing environment increases the level of self-care possibilities due to adapted housing environment such as technology, in-house staff, access to healthy food and socializing with other residents. The housing itself provides informal care, hence, the need for formal care (like home care) 
can be reduced (Woll and Bratteteig, 2017; Woll, 2017). However, because of scarce healthcare resources, many of the residents placed in care housings could have benefitted more from living in nursing homes. This may lead to residents getting increased health issues/declining health over time and to the need for expanded formal care services. During our studies of technology use in practice, we saw that shifting general health conditions challenged the active use of technology.

In the following sections, we present a set of different user stories from our empirical material. Each story illustrates a phase in the elderly care trajectory. We also describe the technologies that are used, and could be used in each phase to increase the technology support in these persons daily life. Figure 5 gives an overview of the whole trajectory with our 10 identified phases viewed in comparison to the municipal care staircase.

\subsubsection{Pre-trajectory / Everyday life}

Pre-trajectory happens before any formal assistance is needed and people live independently and maintain self-care without any need for additional support. Thus, elderly people are in this phase "expected" to do the self-care work without any need of formal care work (Strauss et al., 1982). One example is Ingrid, who is 93 years old and lives in her own house, which she has been living in since she got married to her husband. After her husband died eight years ago, she has been living as selfdependent. Her house has two floors and the staircase connecting the floors has no rails for support when walking the steps. She recently fell and broke her wrist while walking the staircase. Before the accident, she only used extended arm-grasping forceps as a technical aid. She got the arm-grasping forceps from her son, who had bought it in a store with smart home gadgets.

However, after her fall she got a personal safety alarm that her son applied for from the municipality. The alarm alerts her two sons and her brother in cases of emergency. Her safety alarm must be worn around her neck and she find it annoying as she experiences the alarm to be in the way when cleaning the house or carrying out other practical work in the house. Therefore, she often hangs her safety alarm on the kitchen chair. Ingrid loves to be outdoors and tending her garden, but the alarm does not work outdoors so she is afraid of falling again when being outdoors. Otherwise, she is in good general health condition; however, she struggles with a foot that often gets swollen because of a past fracture.

\subsubsection{Trajectory initiation}

We recognize the trajectory starting by an acute accident or illness such as Ingrid's case, where she broke her wrist, and then got a motivation to apply for a personal safety alarm from the municipality to feel safe. Peter, for example, is 83 years old and lives alone in his own house. He suffers from Parkinson disease, which has made him immobile over the last 5 years. He lives close to his sister Martha, who is 5 years younger - however, she has had some health issues because of a hip fracture and a stiffened leg.

Martha has taken care of her brother over the years as his health has worsened, but it is challenging for her to keep two houses. She is often concerned about her brother's health condition. After several negotiations with her brother, she has been able to convince him to get daily support from the local

home care service, and to apply for a personal safety alarm. She expresses that she feels more relaxed after the formal care apparatus has taken over some of the responsibility for her brother.

\subsubsection{Simplifying tools and arrangements}

Simplifying tools and arrangements can greatly improve the level of self-care and ease the informal care. Help in carrying out every day domestic tasks compensates for loss of abilities due to illness or age. Peter is thankful for the support he gets from the home care service as he finds these home visits 
socially stimulating, and he enjoys the fact that somebody else than his sister makes sure that everyday chores are done. He receives both practical assistance of cleaning the house and help with personal grooming, which has been neglected for some time. He experiences the support as something positive. The arrangement with the home care nurses' works fine in the beginning, but after a period of repeated falls in his home, Peter suffers from a hip fracture that require hospital admission.

\subsubsection{Incidents, set-backs and transition}

After being hospitalized for several weeks, Peter needs a short-term stay at a care home, as he is still fragile after the fracture. However, Peter insists that he want to go home, and he is not interested to stay at the care home. His sister feels bad about Peter wanting to return home without her being able to support him, however, she visits her brother as often as possible. Over days, as he is adjusted to the new living environment, he starts to enjoy the good meals he is served, as well as the social activities with other residents. He is dependent on using a wheelchair to get around and he uses a personal safety alarm that he wears around his neck. He often put the safety alarm on the wheelchair handle, as it is not comfortable to wear it when he lies in the bed. One night he has the need go to the bathroom, and he forgets to call the nurse for assistance and falls when he tries to stand on his feet. The night nurse finds Peter on the floor during her fixed night rounds, and nobody knows how long Peter has been lying on the floor.

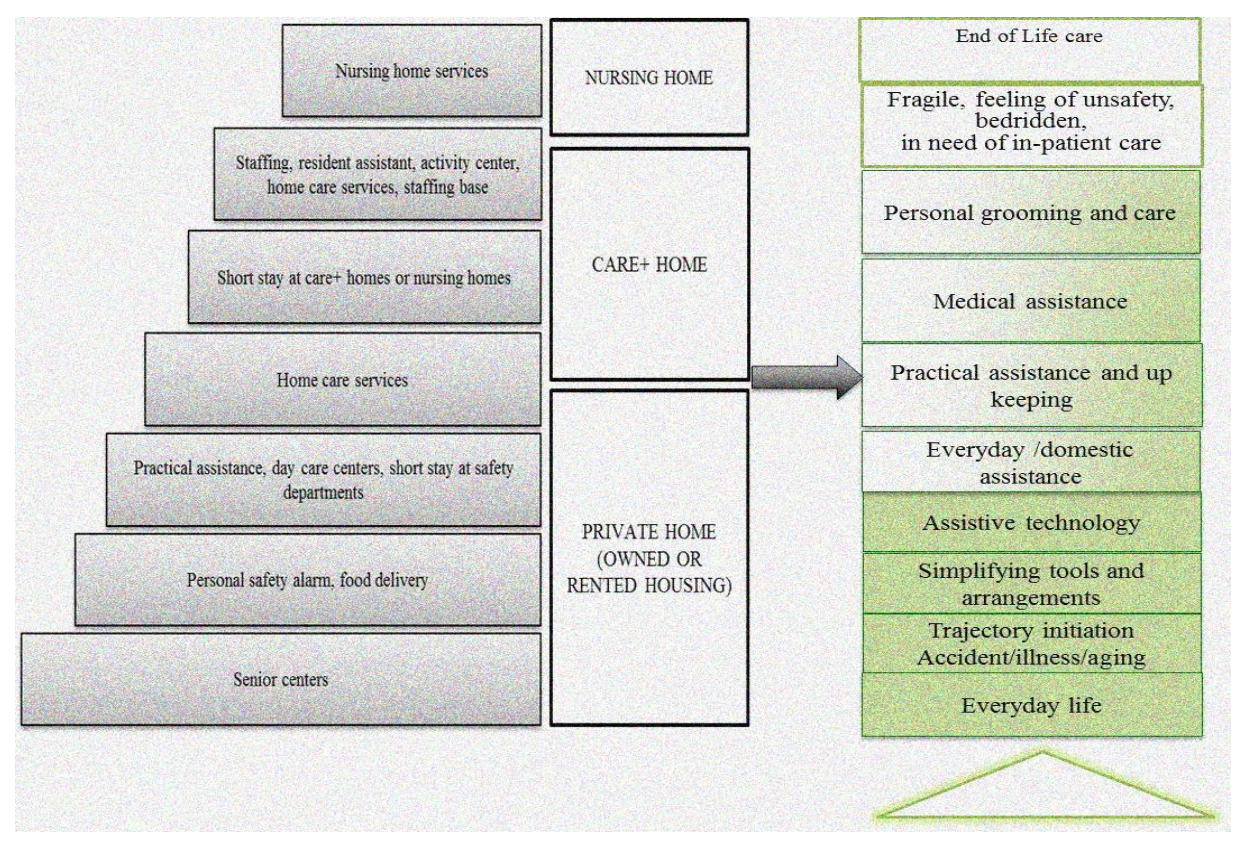

Figure 5. An illustration of the care staircase compared to our technology-supported elderly care trajectory. The green color in the trajectory illustrates the amount of technology use.

\subsubsection{Assistive technology}

The most commonly used assistive technology in elderly care is the personal safety alarm. However, when increased healthcare services are needed, the safety alarm alone is not a sufficient support. To reach the potential of implementing expanded use of technical support to home-dwellers, additional devices are recommended such as an automatic medicine dispenser, a camera for nightly supervisions, various sensors logging normal or abnormal activities, such as sensors logging incidence of falls or sensors detecting if an inhabitant walking outdoors during night time etc. can be beneficial according to individual user needs. During our field studies, we learned that most elderly people are not eager to start using assistive technology before they have an actual need, however when introducing technology 
straight after an acute accident or illness we see that the appropriation of technology is less than its potential. Thus, when a person has a pronounced need for assistive technology, the opportunity to start with additional technologies for preventive purposes should be taken. Moreover, we also have learned that elderly people with moderate health issues are afraid of replacing services with technology as they prefer the personal visits from nurses. They therefore needed to be "invited", "negotiated", "learned" and at some point, also "demanded" (Strauss et al., 1982) to use technology as a part of the service delivery if they express lack of interest for taking the responsibility of self-caring.

\subsubsection{Everyday/domestic assistance}

Persons who enter the elderly care trajectory often experience shifting general conditions, such as Peter. Thus, the capacities to carry out everyday activities can alter from day to day. This needs to be taken into consideration when developing a trajectory for elderly care services. By adding increased technical support in the home, the needs for care can be transformed into more need-based care services. Consequently, on days when an elderly person is having a "good day", it may not be required to receive a physical visit from the home care nurse and self-care activities can be maintained. While in the opposite case, when having a "bad day", e.g., when an elderly person is bedridden, it can be necessary to visit the person for support. There is also a shift towards increased focus on everyday life rehabilitation, so if a person is struggling with e.g., getting dressed or using an assistive tool - the rehabilitation activities are focusing on "teaching" (Strauss et al., 1982) how to best become selfdependent again. Extensive training is required to regain past capabilities, which also involves several types of "patient work" ("expecting", "demanding", "inviting", "negotiating" and "teaching") if the person is not motivated to become self-dependent again. However, sometimes regain of past capabilities are not possible.

\subsubsection{Practical assistance and upkeep}

Following section 6.1.5, elderly people with lack of capabilities in self-caring often need practical assistance in the home as well. This can be done by either private or public service providers. However, when getting formal decision of public services for practical matter there is a need to assess the person's ability of doing practical assistance themselves. This is done by an evaluation of the prospective receiver of such services and also here is rehabilitation in focus. Therefore, some elderly people can get formal decision of doing practical assistance together with the assistant, thus they are "invited" and "learned" (Strauss et al., 1982) how to carry out this work. Those having the capacity in doing cleaning or shopping groceries such as Martha prior her fall in the staircase-can be included as part of an intensive rehabilitation program to regain active aging. However, Peter, who had severe healthcare conditions when living at home needed to be supported differently, and he had practical assistants who took over the responsibility of cleaning and other practical matters.

\subsubsection{Medical assistance}

Ingrid is still active and self-dependent, she has a walker with a seat that support her when she goes to the store on daily basis since she can take a rest whenever she needs it. She also meets her friends in a café every Saturday for a chat. Her hands are shaking but the café personnel help with bringing her coffee and cake to the table. She also gets pre-cooked dinners via the home care service, but her ability to taste disappears and lonely dinners makes her eat and drink too little - she loses weight, gets dizzy and starts falling more often. Lack of liquid makes her catch urinary infection, and after some time she gets a catheter. The home care nurses now visit her four times a day to give her medication and help her get up and go to bed. She sits more and more still in front of her TV - but enjoys the news programs as well as her many visits from the home care nurses. 
Alternative solutions for these formal care services can be voluntary organizations doing social activities with Ingrid and an automatic medical dispenser that reminds her to take the medication timely. However, different municipalities have different services, so in this municipality these offerings where not an option.

\subsubsection{Personal grooming and care}

As Ingrid gets more fragile, she needs help with both personal care and practical matters. She is not able to transfer in or out of the chair (a soft electric chair) and her home has been turned into a workplace for the home care nurses. As she becomes unable to take care of herself, she is offered a short-term stay at a care home (where she has been in the past when she needed a rehabilitation stay after she broke her wrist). This time she does not recover, and it becomes clear that she needs long-term around the clock care.

\subsubsection{In-patient care}

Ingrid moves to the nursing home, and she finally feels safe and sound. On good days, she is helped into her wheelchair to have her meals together with other residents, but on days when she does not feel well she eats her meals in the bed. Like most of the residents in her department, she always keeps her room's door wide open, so she can hear that there are people in the corridor - the sounds of steps make her relaxed. Her health condition is evaluated as worsening, so she got a long-term stay at the nursing home.

Peter is also moved to a nursing home after his latest fall. He has been through a new hospital admission because of the latest fracture, which again resulted in a pneumonia after being bedridden for an extended period. The surgeons were not able to perform the required surgical operation because of Peter's worsening general health condition. To reduce the pain, he is heavily medicated, thus, he is bedridden most of the time and his cognitive abilities become reduced because of the medication.

\subsubsection{End of life care}

Peter is sleeping during most of the days in the nursing home. For the last months, he has been bedridden and is not able to take care of himself, so he needs full in-patient care. He stops eating and drinking during his last week of life. He is sleeping 24/7, and is drifting in and out of consciousness. The nurses assure that Peter does not have any pain during the end of life caring. They gently wash him daily when he lays in bed for his well-being. The nurses also help Peter shifting between different comfortable positions in bed. His mouth is quite dry as he does not drink any water, so they moisturize his mouth regularly to help relieve his discomfort caused by the dryness. His sister Martha is sitting by his side when he dies.

\subsection{Transitions between trajectory phases}

In this sub-section, we make a conceptual proposal on how technology can support people during selfcare, informal care and formal care as the elderly trajectory is traversed. We both look at technical opportunities and fluctuating division of labor between the different care workers. We emphasize how elderly people can make use of technological support in time for them to prolong their habits and preferred ways of living, and hence prolong each of the phases. Moreover, in the last phases in the trajectory the formal care receivers are taking over as the main care provider. We also explain our understanding of transition, and are particularly concerned with the transitions between phases in the 
care trajectory. Our aim is to suggest a way to support the transitions better so that elderly care receivers can traverse the trajectory more smoothly and avoid long transitions that can harm the person's health and well-being.

We start out with illustrating the relationships between self-care, informal care and formal care in Figure 6. Initially, elderly people carry out self-care activities as a natural part of daily life if they master doing so, such as Ingrid presented in the phase "pre-trajectory". Self-care activities for elderly persons living in ordinary homes are often referred to as Activities of Daily Living (ADLs) (Gustafsson et al., 2013) and instrumental Activities of Daily Living (iADLs) (Cromwell et al., 2005). ADLs are learned during childhood and concern activities such as eating, toileting (continence-related tasks including control and hygiene), dressing and undressing, bathing (personal hygiene and grooming), and transferring (movement and mobility) (Gustafsson et al., 2013). These activities require both cognitive and physical abilities, and examples of commonly used technology support of ADLs are furnishing installations supporting adapted living like various extended arm-grasping forceps, grab rails / handles, household aids, wheelchair, walkers, crutches etc. Use of assistive technology can also support and compensate for minor lack of cognitive and physical capabilities by active and passive use of technologies. Most elderly people above 75 years of age have a personal safety alarm in Norway, and the safety alarm can be supplemented with additional fall sensors, door controllers or other sensors that capture normal activities in the home.

iADLs are activities learned during teenage years and include more complex activities like managing finances, handling transportation (driving or navigating public transit), shopping, preparing meals, using the telephone and other communication devices, managing medications, housework and basic home maintenance (Cromwell et al., 2005). Examples of active use of technology support for iADL is digital medicine dispensers, remote telecare for daily exercise both online or pre-recorded videos on the television interface. There are also other kinds of technology support in the home for communication, and more specialized technology support like booking systems to ideal organizations like the Red Cross to get assistance during transportation and / or companion for errands. A vacuum cleaner robot can support users in cleaning the home; lawn mower robot can support the user in tending to the garden. An electronic pill dispenser can send an alert to a formal or informal caretaker if the medicine is not taken within a pre-set time range. The main objective is that elderly people do as much of their self-care activities as they are functionally capable of doing. However, informal care providers like family and friends are essential support for home dwellers for practical and social activities that prevent isolation and loneliness. Younger elderly persons are often not comfortable with visiting senior centers; hence, a visitor friend / volunteer from the Red Cross organization can offers home visits. However, technology can also play a key role as a communication tool between the elderly person and his/her informal providers. In addition, informal caregivers can also receive a predefined subset of the sensor alerts either as the single receiver or in collaboration with formal caregivers. Informal caregivers are most important in bridging the gap between self-care and formal care activities: it is often the relatives who notice disruptions, or gaps between the self-care abilities and the formal care offers as relatives often are the ones who carry out the work in-between. Thus, informal care providers doing practical and social activities often function as the "glue" in the network of care providers. They are also often the ones who articulate the needs of the elderly person when s/he is not able to maintain the self-care level and the level of formal care services must be increased.

The balance of self-care-, informal and formal care activities can vary over time, from a person being completely self-reliant to needing in-patient care. It is a challenge to provide elderly people with sufficient formal services as their need can change on a daily basis. The transitions within and between 
the diverse types of housing arrangements are particularly important as they represent changes in the life of a person that have consequences for the experience of being safe and master everyday life as well as deciding which public healthcare services are available to them. Technology support in care homes is similar to technology support in ordinary homes. However, care homes often have additional in-house services that represent informal care work such as social activities, staff working around the clock in the reception etc. Care homes are designed for adapted living and enhance the residents' possibilities for doing self-care activities. Moreover, care homes have an in-house cafeteria so that the residents have access to "homemade" dinner so they do not have to cook themselves. Modern care homes have also network infrastructure installed, which makes it possible to scale technology usage and add technologysupported services adjusted to the users' needs. In our action research study, the elderly care receivers living outside the care housing were excluded since none of these potential participants had Internet access in their homes. Lack of infrastructure and the quality of the infrastructure itself are important matters when talking about the use of assistive technologies in elderly care. We have seen that some people who live in ordinary homes are provided with comparable services to the in-patient care in nursing home - we also know that some elderly people living in care housing have similar care services as in nursing home. Thus, we argue for the importance of looking at welfare technology use in an overall manner aiming for postponing the time that transfer of housing is needed. Therefore, a similar infrastructure and access to services should not depend on the housing arrangement the person lives in; a robust infrastructure and basic technology-supported services should be provided to everyone traversing the trajectory, and with additional possibilities for expanding services in accordance with the individual needs.

In cases where a person has health issues, the need for formal care services is evaluated according to the user's functional and cognitive abilities. Formal care services are provided by professional healthcare workers to those elderly people who have applied and have received formal decisions about receiving services, e.g., day care center, personal safety alarm, food delivery, practical assistance, home care services, care home, rehabilitation stays and/or short-term or long-term stays in nursing homes. The formal care services are illustrated as a care staircase, as presented in Figure 2 in this paper. In addition, technology-supported care work can support individual user needs, e.g., various sensors for safety and security or smart house installations such as the stove guard etc. Technology can also support and increase communication between the various providers in the care network including staff working at the day care center, home care service staff and staff doing practical assistance in the home. Moreover, technology brings possibilities for control, intervention and logging of incidents along the trajectory's phases. Technology used for alerting and logging adverse events, e.g., like walking outside during night or fall incidents can be an important supplement to other essential information (e.g., the number of hospital admissions) during transitions. Logging night wandering or confused behavior (such as opening the refrigerator door 100 times during a day) should be used as documentation for increasing the level of care.

Careful mapping of technology-supported services to the trajectory's main phases can increase the feeling of safety and mastery in elderly people's everyday life. As mentioned before, aging and disease do not happen in a linear manner; hence, a sudden decline in health (temporary or permanent) should be expected. Lessons learned from the stories of Ingrid and Peter are that relative simple technology adjustments, such as wearing the personal safety alarm around the wrist 24/7 could increase their safety. Moreover, both Ingrid and Peter could benefit from increased assistive technology support. For example, Ingrid could benefit from using a digital personal safety alarm that works both indoors and outdoors, in addition to fall sensors in her home. Peter could potentially have prevented some of his falls or at least have reduced the response time of assistance if he had been equipped with preventive 
fall sensors in his bed or on the floor, in addition to regular fall sensors. We suggest introducing passive use of technology as an addition to the actively used personal safety alarm during the initial phases of the trajectory (see Figure 6 and the phase "assistive technology"). Our proposed trajectory model in Figure 7 includes a mix of active and passive use of technology-supported services directed to the diverse housings. The combination of active and passive use of technology represents redundant solutions that can support the users' safety when spanning two of the trajectory phases - like when being in transition. In this way, it is the person's capabilities, and not the trajectory phases that decide what and how technology is used.

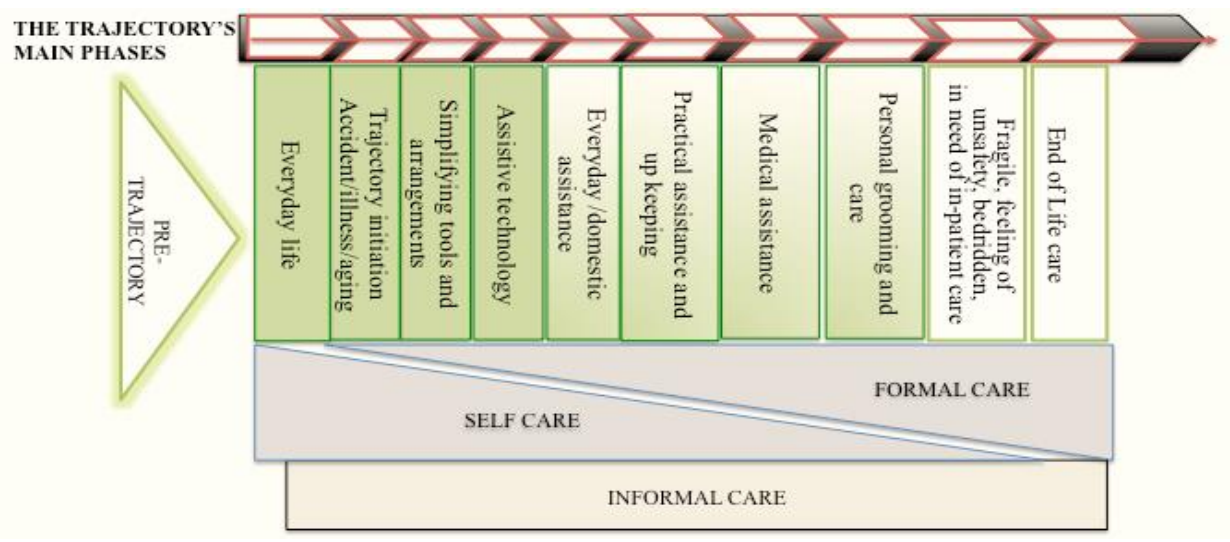

Figure 6. An illustration of the collaborative effort of self-care, informal care and formal care, and the relationships between these in conjunctions to the main phases in the overall elderly care trajectory.

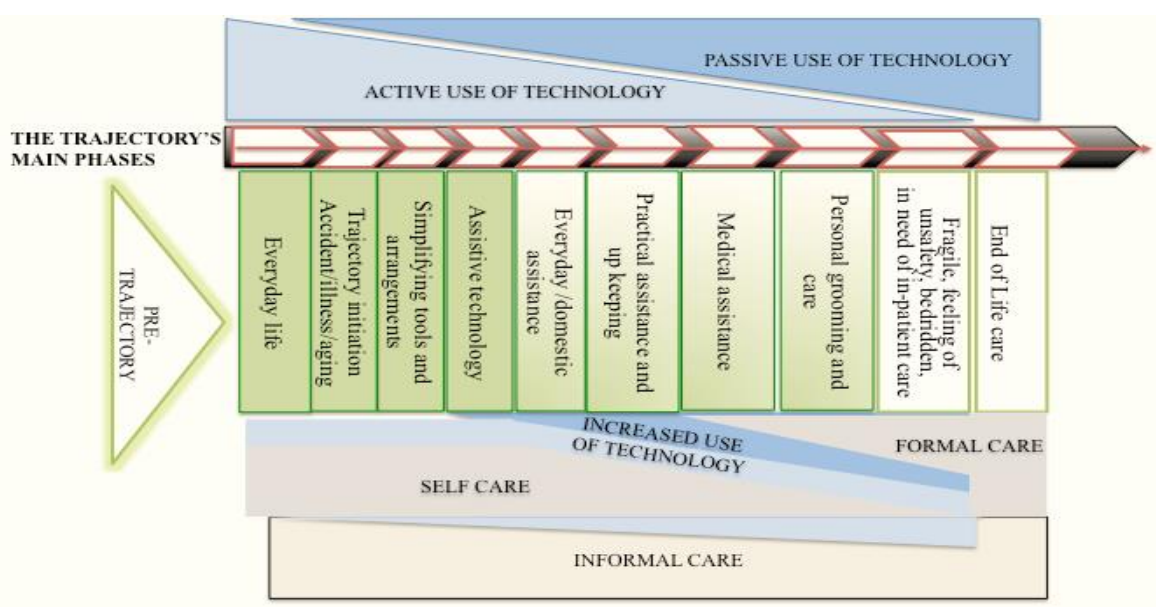

Figure 7. The figure shows how technology provides layers of increased support in the care services including self-care, informal care and formal care, prolonging elderly persons' time within a phase of the trajectory.

Figure 8 (below) illustrates how technology can enhance the self-care, informal care and formal care so that the time within each phase is potentially prolonged for the elderly persons traversing the trajectory. The level of support can be designed as layers of alternative solutions for a specific service, which then better can match altering user needs and fit a person's capacities and general condition. One example is the daily activity of shopping groceries, which is in the pre-trajectory phase (this example could also be illustrated in the care housing phase). Many elderly people with mobility or balance disorders use a walker for support when walking and going shopping. Several walkers are equipped with a basket for storage, e.g., to carry home groceries. If an elderly person does not master to physically go to the shop, $\mathrm{s} / \mathrm{he}$ can shop groceries online and get the groceries delivered on the door. Moreover, if shopping groceries online is found difficult or impossible because of poor general condition, the person can get 
support from volunteer helpers or family members. In Figure 8, we illustrate some examples of layers of services connected to the housing situation of an elderly person.

A challenge with the approach presented in Figure 8 is to find solutions that fit individual needs. First and foremost, the services need to match a user's actual needs and capacities. There is not one universal solution that fits all users. The formal care workers need to evaluate each user according to their actual needs. Types of interventions should be discussed and agreed upon in collaboration with the formal care workers e.g., home care nurses as they have the responsibility for formal services included in the trajectory. Thus, even if formal care workers delegate work responsibility to the self-care worker or informal care worker it is still the formal care worker, who has the main responsibility (and needs to be the back-up worker). Thus, the formal care worker can get the blame if not providing services to people in need of healthcare support. It is the formal care workers that can act on information according to their knowledge about the patients and therefore the gathered information from sensors need to have relevance. The choice of what technology to install for passive use of welfare technologies e.g., sensors to support the safety and security will differ from person to person. For example, some users will need technical support when they go out of bed during night while others can be sufficiently supported by a sensor who gives an alert if the user is absent from the bed in an abnormal time-period during night.

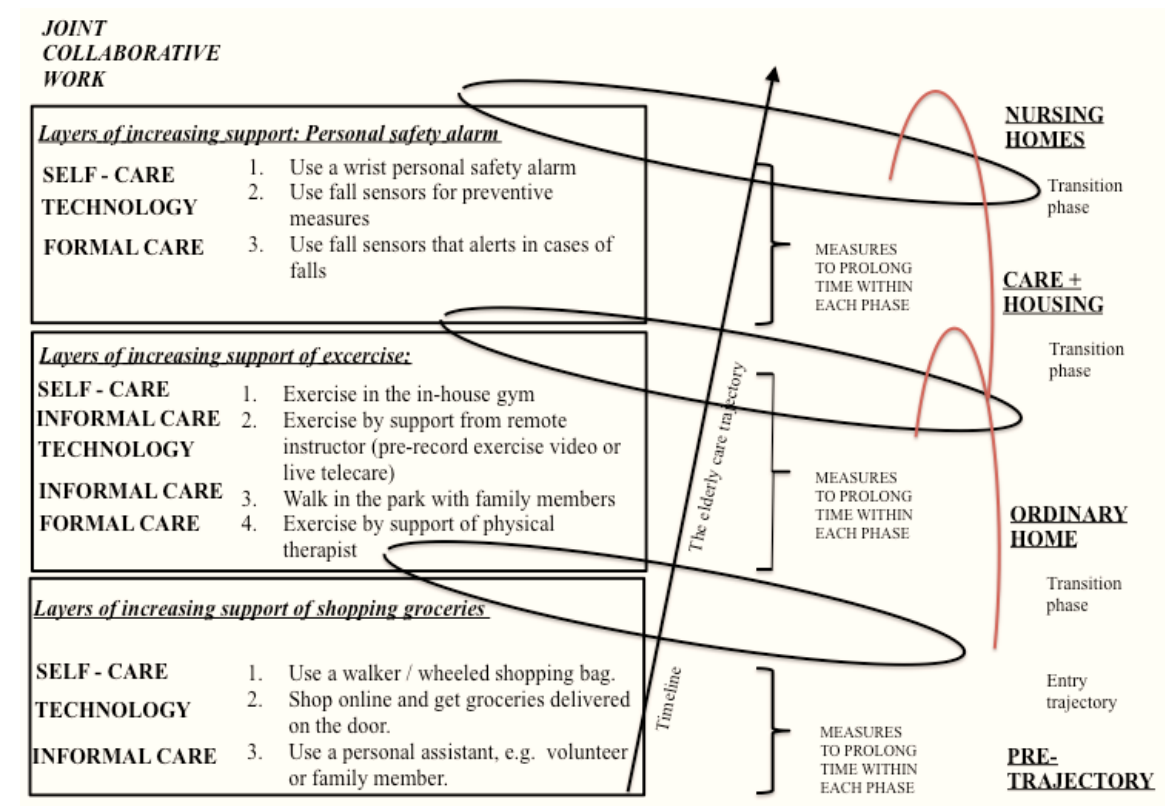

Figure 8. The figure illustrates layers of increased support for self-care, informal care and formal care work within distinct phases of the trajectory.

We argue that there is a need for several types of technologies for the same service in order to find a solution that fits a user's preferences. For example, a specific design of a digital medicine dispenser is not necessary intuitive for all users, so distinct types need to be introduce if one type is found hard to learn.

The technology-supported services for critical services such as camera and sensors for digital supervision must work 24/7. If they do not work as planned or fail to alert when critical incidences take place, the users health and well-being can be at risk. This require self-testing solutions that alerts in cases when equipment is not online. This also calls for a technical staff supporting care workers to maintain equipment and make sure that the technology-supported services are robust. 


\section{Discussion}

The proposed comprehensive elderly care trajectory model is based on our empirical data showing that the use of assistive technology in practice is challenged by the fact that most elderly people with pronounced health issues, also have unstable and shifting needs for care and support. Thus, from observations made during the fieldwork, we have seen that appropriation and use of welfare technology is difficult for elderly end-users (e.g., see section 5.2). Accordingly, current technical support is not robust enough to support the various users' needs. We have suggested a trajectory that aims to express how to better support elderly people despite altering user needs and increasing needs for care for shorter or longer periods. The trajectory shows that self-care, informal care and formal care are intertwined, but also shifting during the elderly care pathway. The trajectory tries to combine resources of the care receiver and informal care providers with the municipal care staircase model for the individual's right to formal care services. The trajectory's phases therefore relate heavily to the different housing arrangements offered in the care staircase model: ordinary homes, care housing, and nursing homes. However, we note that most self-care and informal care work - and to some extend also formal care work - are provided while people live in their homes, be it ordinary homes or care homes. The three housing arrangements correspond to how the public healthcare system responds to decreasing abilities for self-care by means of housing, technologies of various sorts, and healthcare services.

\subsection{The mix of self-care, informal care and formal care}

During the initial phases of the trajectory, the level of self-care is expected to be high with support of informal care workers. The increased focus on self-care work makes Bratteteig and Wagner (2013) suggest seeing care work as distributed collaborative work where the care receivers' work is just as important as other care work within the larger network of care. Our studies support their findings, and the increased focus on active aging and successful aging has brought a lot of pressure on elderly people to live in certain ways, maintain a healthy lifestyle, and actively take care of themselves.

This is echoed by Proctor et al. (2014), who argue that successful aging is socially accomplished by collaborative efforts of elderly people and their care network. To transform current services into more efficient ones, we found it useful to add self-care, informal care and expanded use of technology into the elderly care trajectory. This makes us more aware of the collaborative effort involved in the practices of elderly care, and brings awareness to the number of people involved: the care receivers, their relatives or voluntary network of informal providers, and the formal care providers. However, for services having an interface to formal care services, like when care work is distributed back to the care receiver or informal care workers e.g., in the initial or middle phases of the trajectory it must be agreed upon who has the responsibility if the work is not completed. The roles must be defined and agreed upon for all the partakers of the collaborative care work. We stress that the various care workers have distinct roles and responsibilities and (as illustrated in Figure 6 above) the formal care workers have the main responsibility during setbacks and the latest phases in the trajectory. Earlier on in the trajectory the care receiver is expected or demanded or negotiated or trained into carrying out self-care or patient work (Strauss et al., 1982) by the support of technology if having the capacity - while formal care workers and informal care workers can support them when needed. It is known that when an elderly person moves into a nursing home, their relatives are not as actively participating as when she/he was living at home. Thus, it is essential to include the relatives or voluntary resources to accomplish higher involvement of collaboration when elderly people prolong the time they can live in their own homes, until they at some point may need as much services similar to in-patient care. The many layers of support 
require formal care workers on call e.g., using central alarm response units as well as a mix of different care workers.

The threshold of getting access to formal care services have increased over the years. Receiving home care services or assistive housing requires more complex healthcare needs compared to the entry to formal services two decades ago. What does it mean for the care trajectory? In practice, it means that the trajectory needs to include the work of the elderly person and his/hers family and voluntary resources as they get more responsibility during the earlier phases of the trajectory. In addition, assistive housing is introduced as an offer to become more self-dependent with all the facilitation that comes along with the housing, however, we have seen that people who get access to assistive housing often have increased healthcare issues so not everyone is able to be self-dependent just by the support of the housing facilities. Home care services are introduced late in the trajectory. As mention above, two decades ago the home care nurses did both social visits and sometimes practical tasks like cooking dinner, but today these tasks are outsourced. The home care services were more generous in the past; now the care receivers get the lowest level of needed care services. This is reported to be a result of the trouble of taking away services that were formally provided. Consequently, when a person started receiving care services the services become permanent even if not needed any more. Today, it is more common to provide comprehensive services in a brief period to get the care receiver stable and selfdependent. The formal care services are taken away when the rehabilitation period is over. It is seen that the conceptual trajectory is of importance to maintain all the work needed from the various care resources than the traditional ones. However, when a person moves to a nursing home it is the formal healthcare workers that are the main caregivers. Solutions from the Netherlands and their dementia village concept based on the use of also voluntary resources are discussed. The nursing home buildings are designed more "inviting" by creating social spaces for the local community. Thus, the future trajectory can be more configured to rely on voluntary resources also in the institutional setting, rather than only during initial phases of the trajectory.

Our elderly care trajectory is in line with Fitzpatrick and Ellingsen (2013), who argue that moving technology into the home brings attention to self-care activities. The shift towards technology-supported care can reduce the number of home visits: the benefits of technology-supported care are only gained when technology replaces other tasks like one or several home visits. However, we argue that this shift will make the nurses prioritize home visits to those elderly care receivers that need them the most, e.g., elderly people that need support with personal grooming and care. Hence, elderly people who need extensive basic services from nurses that cannot be replaced by remote technological assistance will still need visits. Like Bratteteig and Wagner (2014), Piras and Zanutto (2010) discuss, recently healthcare activities have been re-delegated from healthcare workers to the patients and particularly to elderly care receivers. The care receivers need tools to handle this increased responsibility, and we argue that they need solutions that are redundant to the tools to secure their safety and security. The shift towards increased responsibility for elderly people who can take the responsibility, needs to be supported with backup solutions (such as passive use of technology and central alarm response units) to safe-guard situations when they experience acute illness or sudden decline in their health condition with temporary setbacks of self-care work e.g., if a person is hospitalized or needs other assistance for recovery. We have chosen to exclude hospitals as an element in the elderly care trajectory, but we are aware that hospitalization and repeated re-hospitalization is an essential factor in the assessment of an individual's functional abilities. Moreover, most elderly people experience hospitalization in the End of Life Care (EoLC) (Gabrielsen, 2013). 
The distributed collaborative nature of elderly care is also discussed by Petrakow (2007), who argues that home care work is more complex than hospital work as work activities in the home take place in a context that is difficult to change. One of several advantages of living in care homes is that the architecture is designed for assistive living, which makes it easier for the care providers to carry out their work. However, universal design of an apartment does not compensate for the fragmented nature of the current elderly care work. Thus, there is a need to explore alternative care models that include formal care services but also emphasize self-care and informal care. We argue that our proposed trajectory gathers the overall resources for caring into an overall elderly care trajectory and its accompanying infrastructure. This conceptual design can be used to support better collaboration, as it brings awareness of who does what; it can be used to improve the coordination of work activities between different providers within the trajectory. We also recommend equipping housing for elderly people with the comprehensive trajectory in mind by adding layers of support as the trajectory unfolds. The proposed trajectory can therefore be used as a tool for both planning the necessary infrastructure as well as for the timing the introduction of assistive technology to the elderly people.

\subsection{Transitions in the trajectory}

The main objective for designing the trajectory has been to make the formal healthcare services more accessible for elderly people. In addition, we wanted to make it easier for elderly people to understand which healthcare services are available to them at various points in time (when they fulfil a set of requirements) and what they can do to prevent or postpone the transition to the next phase of the care trajectory. Therefore, the trajectory can be used as a tool when communicating with elderly people about their elderly care pathway (which involves potential illnesses and decline of abilities). Our focus is on mastery, defined as "a human response to difficult or stressful circumstances in which competency, control, and dominion have been gained over the experience of stress." (Younger, 1991, p. 76). In the proposed elderly care trajectory, we have tried to "translate" the formal staircase into a seamless "journey" that includes the diverse housings. We emphasize that the transitions between these formal steps (e.g., the change between diverse types of housing) are particularly important as they can be experienced as problematic by the elderly people. Hence, the transitions between the main phases are essential and critical parts of the trajectory. Smooth transitions can lower the threshold and ease the elderly person's experiences of traversing the elderly care trajectory. Moreover, transitions are not necessarily a linear process, as they can be both horizontal (traversing the main phases) and vertical (traversing within a specific main phase) depending on the elderly person's condition and prospect of recovery. Thus, elderly people can experience shifting health conditions, but still be able to stay in the same phase of the trajectory with increased formal care for a shorter or longer period. For example, for a person who suffers from dementia the health condition can vary daily according to other healthcare issues, everyday incidents, or contextual situations. The (slightly dement) person's functional abilities will, however, last longer if $\mathrm{s} / \mathrm{he}$ can rely on habits and routines in a well-known environment instead of moving to a new house where everything is new and unknown, and possibly confusing. The variations within a phase are also important in our trajectory, mostly shifting the forms of care involved (self-care, informal and formal care). We see technology as an essential tool for supporting elderly people in prolonging a phase and in transition between phases. We therefore have added technologysupported services throughout the trajectory.

There is a range of ethical dilemmas embedded in the use of assistive technology. How long do people want to live independently in their own home if they are completely dependent on technology: what does "independently" mean? We know that as a society we need facilitation so that more people can 
take care of themselves, and live longer in their own homes because of the increased life expectancy and proportion of elderly people compared to the working part of the population. There are not enough care providers for maintaining current care practices. However, how long should we aim for elderly people to postpone the time lived in ordinary homes when it is sometimes more responsible to let go of independent living and transfer to the next phase in the trajectory? The health authorities aim for most citizens to live in their own homes until the end of the trajectory, by also bringing back the dying phase to the home (Senior report, 2014). Currently, most elderly people die during nursing home stays or during hospitalization. Thus, only the sudden or unexpected deaths of elderly people take place in the home (with exceptions). Dying has become alienated for the family. Elderly people who decide to stay in their homes also after they have lost the abilities needed for independent living are provided with extensive home care services, almost comparable to in-patient care as a replacement for nursing home services. We argue that independent living or terminal care in the home are justifiable if the person is feeling safe and are receiving sufficient healthcare services. However, when observing the lack of technology support beyond the personal safety alarm among the user group of home-dwellers, it does not look medically responsible when we know that some of the home-dwellers have needs for services comparable to in-patient care. We argue that to succeed in prolonging elderly people in living in ordinary homes from the initial start to the end of the elderly care trajectory, in a safe and health professional sound manner it is a necessity to increase the passive use of technology by bringing automated $24 / 7$ services into their homes.

\subsection{Identifying factors that facilitate or hinder attainment of goals}

In our studies of elderly care practices and use of technology, we have experienced that introduction of active use of technology often take place in the later phases of the care trajectory. Aaløkke Ballegaard et al. (2006) reflect on the role of assistive technology and they also argue that such technologies are often introduced too late for the elderly people to make use of, e.g., in acute phases. Their research supports our findings from observing the oldest old and people with cognitive impairment struggle with using technology actively, e.g., the personal safety alarm or the tablet. An important problem with technologies designed to compensate for lost/decline in abilities is that people approach the technology when the decline in abilities is pronounced, making it hard for them to learn or utilize its potential. The technological support needs to be in place before the problem gets too big, in time for them to prolong their habits and preferred ways of living. The trajectory can provide advice for when to introduce technology that may enhance abilities (and potentially increase the range of possible activities): giving a dizzy and fragile person a roller, for example, supports walking and may (re-) introduce the abilities for going shopping, exercising, going for walks and visits that was difficult without the roller. In this way, the technology prolongs abilities and may prolong the current phase in the care trajectory. A hearing aid or a wheelchair, for example, do more than supporting or enhancing a weak ability: it may increase the abilities by replacing a function that is disabled (hearing, walking). Replacing is obviously stronger than supporting, but several reports show that training is necessary for being able to make use of new abilities, hence introducing hearing aids before becoming deaf or exercising using a wheelchair introduces a higher threshold of technology support than merely supportive technologies do (Joshi and Bratteteig, 2016). However, we want to stress that we have experienced that old age itself does not restrict active use of technology, rather it is illness and health conditions combined with bodily changes that follow from old age.

Ideally, all assistive technologies should be introduced to the younger elderly in the pre-trajectory phase, when their functional ability is still intact so that they know how to operate the technology before they 
really need it. This is a user challenge as an acute situation is acute and it is difficult to foresee when the introduction should be done in practice. However, we suggest identifying services that the younger elderly people could find appropriate and useful, e.g., social contact, access to volunteer services and social arenas, or online grocery shopping. Thus, when signs and symptoms of reduced functional abilities are visible, the elderly people have established habits that enable them to continue using the services. The services can also be expanded to include more services aimed at lower functional levels, but designed in line with the habituated services. Self-care and follow-up care after rehabilitation or hospital stays will then be continuation of previous (use) practices. For some users, a late introduction of technology has resulted in non-use, as they do not understand how to use the technology. When a technology is introduced as a follow-up service after an acute care situation, the user often experiences a (temporary) decline in capabilities that makes understanding and learning new routines troublesome. Thus, modern technology demanding active use should therefore be introduced first when the health condition is stabilized again. Thus, passive use of technology is more appropriate shortly after acute phases. We have designed the trajectory with main phases and transitions between these phases to address technology needs before they are evident and acutely needed. An important implication from our studies is that we suggest redundant solutions (e.g., sensors) to prolong the phases of the trajectory as well as postponing transitions to later trajectory phases. Redundant solutions can be to install automated technology-services for passive use of welfare technologies e.g., sensors to support the safety and security of users having unstable user needs, thus, shifting capabilities in operating technical solutions. Automated services aimed at passive use of technology are particularly useful in the transition between phases, e.g., when the elderly person needs short or long-term stay at care homes or nursing home for safety and well-being. We suggest that the levels of automation contain various combinations of active and passive use of welfare technologies, or varying levels over time as user needs can be shifting. The aim is to improve the fit between the elderly users' need for support in daily life, in accordance to the amount of technological support. The log of alarms and alerts concerning falls or wandering outdoors during night can be useful for documenting the individual physical and cognitive capabilities. The gathered information from sensors and alarms should be used for action when analyzing user needs and capabilities; an automatic early warning system based on frequency or number of alarm incidences can indicate a need for additional care support. The elderly person or his/her relatives may not be aware of the situation or the elderly person may not be explicit about her/his needs for care services.

Active use of technology should preferable be based on simple interaction mechanisms tailored to the elderly population: what they find easy to learn and easy to use, e.g., an automated medicine dispenser with intuitive user interface. Designing interaction mechanisms that are perceived as simple and even intuitive by the user group requires interaction design tailored to the elderly people. Design based on what the generation of elderly people consider intuitive or easy suggests building interaction mechanisms based on well-known representations and actions (Joshi and Bratteteig, 2016). An example is a student project in the care housing about designing a digital radio with well-known interaction mechanisms: old-fashioned turn switches that are grooved for a better grip, with resistance when turning the switch, and with a click when the exact position is reached (Joshi and Bratteteig, 2016). Modern technology is sometimes not appropriate for elderly people, and they need adjusted design in order to be found useful.

We disagree with Aaløkke Ballegaard et al. (2006)'s argumentation to build services on technology that is familiar to the users: when we used the television as a platform for telecare the users expressed strongly "do not mess with my television". We learned by the action research study the importance of designing and building services on dedicated technologies for critical services that requires robust 
solutions working 24/7. Familiar technology in the home is mainly used for other purposes so when adding additional services to a device used for other objectives, it both increases the complexity in operating the technology and disturbs its regular use (Joshi and Woll, 2015a). However, we see that solutions can be found to make the switch from one source connected to the television to another less complicated. In our study the main issue with the television was that the elderly participant did not like the interference with their TV as they used the television to watch television programs as the first and foremost purpose of the technology. Moreover, the stationary position of the television made the use troublesome, e.g., during days when the care receivers were bedridden. When testing the tablet as a backup solution for the stationary one for telecare sessions, we experienced that the participants did not use the tablet as a mobile device. They never brought the tablet to their bed side when going to bed in the evening. The tablet was often placed at the "tablet table" in the living room or the tablet was out of function because of flat battery. Critical healthcare services such as home care services require robust technical solutions that work 24/7. The technical equipment used for home telecare cannot fail. During our study with the telecare solution we experienced loads of extra work because the participants often disconnected the television from the power outlet during nighttime for safety precautions, or the camera was unplugged, or they were busy watching a television program, so they asked to postpone the telecare call etc. All-in-all the extra work to make the solution work was not efficient use of time, so after the pilot study ended the telecare solutions for delivery of home care services was rejected. We concluded that technical solutions for critical healthcare services require dedicated technology to achieve a robust solution working 24/7 - and with a backup battery. However, we do want to emphasize that we acknowledge the potential of using familiar technology such as the television as a platform for noncritical services such as social communication.

\section{Conclusion}

In this paper, we have proposed a comprehensive elderly care trajectory model based on Strauss and Corbin's trajectory model and empirical studies of elderly people's use of assistive technologies. We recognize the current public care staircase as restricted by not bringing awareness to 1) the shared collaborative work of elderly care, 2) the transfer between the different level of care (illustrated as steps and for some experienced as gaps) and 3) the future needs for expanding technology-supported services. Our trajectory fits with the municipal care staircase by including different types of housing and increasing levels of care services. However, our trajectory brings attention to the collaborative care work of self-care, informal care and formal care, and not merely formal services. We recognize assistive technologies as measures to prolong each phase in the trajectory as well as essential tools to ease the transition between the phases. The trajectory highlights the importance of combining active and passive use of technologies to safeguard that the users are supported during their everyday life. Our proposal connects technology-supported services to each of the phases of the elderly care trajectory, aimed at expanding self-care and informal care by increasing functionality and capabilities by enhanced technology support. We also highlight design suggestions to better support elderly people in appropriation of technology-supported services. These are design 1) that include levels of automation, 2) that include simple interaction mechanisms, and 3) critical services on dedicated technologies aiming for robust solutions working 24/7. We argue for a trajectory that includes increased technologysupported care services for the following purposes:

- For systematic use of tools increasing the capabilities for self-care and informal care work

- For earlier introduction of assistive technology to younger elderly people 
- To support users with various technology-assisted services regardless of housing arrangement

- To combine active and passive use of technology to achieve redundancy that enhances safety and security in each phase of the trajectory,

- To support elderly people in transitions between phases, including making a better basis for decision-making in transitions concerning the need to traverse the trajectory or stay put

- To delegate care tasks and responsibility back to care receivers and their informal care providers. Thus, introduction of technology can be used as a tool for the distribution of care work between the different care workers (self-care, informal care and formal care workers)

Future research is required to develop a more detailed guideline for operationalizing the trajectory, its phases and the phases' transitions. We also aim to develop and test various aspects of the trajectory model in real-life practices to explore the robustness of the model further.

\section{Acknowledgements}

We want to acknowledge the Norwegian Research Council who supported this research by the grant number 220111 and titled "Developing new ICT to support and assist elderly people in private and public spaces at care housing".

\section{References}

Aaløkke Ballegaard, Stinne; Jonathan Bunde-Pedersen; and Jakob E. Bardram (2006). Where to Roberta? Reflecting on the Role of Technology in Assisted Living. In A. Mørch et al. (eds.): Nordichi'06. Proceedings of the 4th Nordic Conference on Human-Computer Interaction 2006, Oslo, Norway, 14-18 October 2006. New York: ACM, pp. 373-376.

Aaløkke Ballegaard, Stinne; Thomas Riisgaard Hansen; and Morten Kyng (2008). Healthcare in everyday life: designing healthcare services for daily life. In B. Lee at al. (eds.): $C H I$ ' 08 . Proceeding of the twenty-sixth annual SIGCHI conference on Human factors in computing systems, Florence, Italy, 05-10 April, 2008. New York: ACM Press, pp. 1807-1816.

Alaoui, Malek; Myriam Lewkowicz; and Ahmed Seffah (2012). Increasing elderly social relationships through TV-based services. In G. Luo and J. Liu (eds.): IHI'12. Proceedings of the 2nd ACM SIGHIT International Health Informatics Symposium, Miami, Florida, USA, 28-30 January, 2012. New York: ACM Press, pp. 13-20.

Amsha, Khuloud A.; and Myriam Lewkowicz, (2016). Shifting Patterns in Home Care Work: Supporting Collaboration Among Self-Employed Care Actors. In A. De Angeli, L. Bannon, P. Marti, S. Bordin (eds.): COOP`16. Proceedings of the 12th International Conference on the Design of Cooperative Systems, 23-27 May 2016, Trento, Italy. Cham: Springer International Publishing AG, pp. 139-154.

Alzheimer's Association (2015). What Is Alzheimer's?

http://www.alz.org/alzheimers_disease_what_is_alzheimers.asp. Accessed 10 January 2018.

Axelrod, Lesley; Geraldine Fitzpatrick; Jane H. Burridge; Sue J. Mawson; Penny P. Smith; Tom Rodden; and Ian W. Ricketts (2009). The reality of homes fit for heroes: design challenges for rehabilitation technology at home. Journal of Assistive Technologies, vol. 3, no. 2, January 2012, pp. 35-43. 
Bardram, Jakob E. (2000). Temporal coordination — on time and coordination of collaborative activities at a surgical department. Computer Supported Cooperative Work (CSCW). An International Journal, vol. 9, no. 2, May 2000, pp. 157-187.

Bossen, Claus; Lars Rune Christensen; Erik Grönvall; and Lasse S. Vestergaard (2013). CareCoor: augmenting the coordination of cooperative home care work. International Journal of Medical Informatics, vol. 82, no. 5, May 2013, pp. 189-99.

Center for diseases control and prevention (CDC) (2018). People 65 Years and Older \& Influenza. http://www.cdc.gov/flu/about/disease/65over.htm. Accessed 10 January 2018.

Corbin, Juliet M.; and Anselm L. Strauss (1991). A Nursing Model for Chronic Illness Management Based upon the Trajectory Framework, Scholarly Inquiry for Nursing Practice: An International Journal, vol. 5, no.3, February 1991, pp.155 - 173.

Cromwell, David A.; Kathy Eagar; and Roslyn G. Poulos (2003). The performance of instrumental activities of daily living scale in screening for cognitive impairment in elderly community residents. Journal of clinical epidemiology, vol. 56, no. 2, February 2003, pp. 131-137.

Culén, Alma L.; and Tone Bratteteig (2013). Touch-Screens and Elderly users: A Perfect Match? In L. Miller at al. (eds.): ACHI'13. Proceedings of the Sixth International Conference on Advances in Computer-Human Interactions, Nice, France, 24 February - 1 March 2013. Print: IARIA XPS Press, pp. $460-465$.

Daatland, Svein O.; and Berit Otnes (2014). Housing oriented elderly care: Development trends, Report, vol. 16, 2014, Oslo: NOVA

Dalgaard, Lea G.; Erik Grönvall; and Nervo Verdezoto (2013). MediFrame: A Tablet Application to Plan, Inform, Remind and Sustain Older Adults Medication Intake. In C. C. Yang and S. Ananiadou (eds.): ICHI'13. Proceedings of IEEE International Conference on Healthcare Informatics, Print: IEEE, pp. 36-45.

Dewsbury, Guy; Mark Rouncefield; Ian Sommerville; Victor Onditi; and Peter Bagnall (2007). Designing technology with older people. Universal Access in the Information Society, vol. 6, no. 2, August 2017, pp. 207-217.

Directorate of Health (2013). Welfare technology. Technical report on the implementation of welfare technology in municipal healthcare: 2013-2030. Print: Norwegian Directorate of Health.

Egger, Edeltraud; and Ina Wagner (1992). Time-Management: A case for CSCW. In J. Turner and R. Kraut (eds.): CSCW'92. Proceedings of the ACM Conference on Computer-Supported Cooperative Work, Toronto, Canada, 31 October - 4 November 1992. New York: ACM Press, pp. 249-256

Engeström, Yrjö; Ritva Engeström; and Tarja Vähääho (1999). When the center does not hold: the importance of knotworking. In S. Chaiklin et al. (eds.): Activity theory and social practice. Aarhus: Aarhus University Press, pp. 345-374.

Farshchian, Babak A.; Thomas Vilarinho; and Marius Mikalsen (2017). From Episodes to Continuity of Care: A Study of a Call Center for Supporting Independent Living. Computer Supported Cooperative Work (CSCW), vol. 26, pp. 309-343. 
Fitzpatrick, Geraldine; and Gunnar Ellingsen (2013). A review of 25 years of CSCW research in healthcare: Contributions, challenges and future agendas. Computer Supported Cooperative Work (CSCW): The Journal of Collaborative Computing and Work Practices, vol. 22, no. 4-6, AugustDecember 2013, pp. 609-665.

Fries, James F. (2002). Reducing Disability in Older Age. JAMA, vol. 288, no. 24, pp. 3164-6. doi:10.1001/jama.288.24.3164.

Gabrielsen, Bjørn (2013). Health services in end of life care. In J. Ramm (ed.): Elderly people use of healthcare services, Statistics Norway, no. 137. Print: Oslo.

GBD (2013). Global, regional, and national age-sex specific all-cause and cause-specific mortality for 240 causes of death, 1990-2013: A systematic analysis for the Global Burden of Disease. Study 2013. http://www.thelancet.com/pdfs/journals/lancet/PIIS0140-6736(14)61682-2.pdf. Accessed 10 January 2018.

Gibson, Grant; Claire Dickinson; Katie Brittain; and Louise Robinson (2014). The provision of assistive technology products and services for people with dementia in the United Kingdom. Dementia, vol. 0 , no. 0 , pp. 1-21.

Gustafsson, Susanne; Kajsa Eklund; Katarina Wilhelmson; Anna-Karin Edberg; Boo E.A. Johansson; Greta Häggblom Kronlöf; Gunilla Gosman-Hedström; and Synneve Dahlin-Ivanoff (2013). LongTerm Outcome for ADL Following the Health-Promoting RCT- Elderly Persons in Risk Zone. Gerontologist, vol. 53, no. 4, pp. 654-663.

Jeste, Dilip V.; Monika Ardelt; Dan Blazer; Helena C. Kraemer; George Vaillant; and Thomas W. Meeks (2010). Expert Consensus on Characteristics of Wisdom: A Delphi Method Study. The Gerontologist, vol. 50, no. 5, pp. 668-80. doi:10.1093/geront/gnq022. PMC 2937249.

Joshi, Suhas G.; and Tone Bratteteig (2015). Assembling fragments into continuous design. On participatory design with old people. In H. Oinas-Kukkonen et al. (eds): SCIS 15. Springer Lecture Notes in Business Information Processing, vol. 223, pp. 13-29.

Joshi, Suhas G.; and Anita Woll (2014). A Collaborative Change Experiment: Telecare as a Means for Delivery of Home Care Services. Design, User Experience, and Usability. User Experience Design for Everyday Life Applications and Services. Lecture Notes in Computer Science, vol. 8519, pp. 141-151.

Joshi, Suhas G.; and Anita Woll (2015a). A Collaborative Change Experiment: Diagnostic Evaluation of Telecare for Elderly Home Dwellers. Digital Human Modeling. Applications in Health, Safety, Ergonomics and Risk Management: Ergonomics and Health, Lecture Notes in Computer Science, vol. 9185 , pp. 423-434.

Joshi, Suhas G.; and Anita Woll (2015b). A Collaborative Change Experiment: Post-experiment evaluation of Home Telecare for Elderly Home Dwellers. In T. Ahram, W. Karwowski, D. Schmorrow (eds.): AHFE'15. Proceedings of the 6th International Conference on Applied Human Factors and Ergonomics (AHFE), Las Vegas, USA, 26-30 July 2015. Print: Procedia Manufacturing, vol. 3, pp. 82-89.

Grönvall, Erik; and Nervo Verdezoto (2013). Beyond self-monitoring understanding non-functional aspects of home-based healthcare technology. In F. Mattern and S. Santini (eds.): UbiComp'13. 
Proceedings of the 2013 ACM international joint conference on Pervasive and ubiquitous computing, Zurich, Switzerland, 8-12 September 2013. New York: ACM, pp. 587-596.

Hamblin, Kate A. (2010). Changes to Policies for Work and Retirement in EU15 Nations (1995- 2005): An Exploration of Policy Packages for the 50-plus Cohort. International Journal of Ageing and Later Life, vol. 5, no. 1, pp. 13-43.

Harman, Denham (1991). The Aging Process: Major Risk Factor for Disease and Death. Proceedings of the National Academy of Sciences of the United States of America, vol. 88, no. 12, June 1991, pp. 5360-5363.

Häikiö, Juha; Arto Wallin; Minna Isomursu; Heikki Ailisto; Tapio Matinmikko; and Tua Huomo (2007). Touch-based user interface for elderly users. In A. D. Cheok and L. Chittario (eds.): MobileHCI '07. Proceedings of the 9th international conference on Human computer interaction with mobile devices and services, Singapore, 09-12 September 2007. New York: ACM, pp. 289296.

Heart, Tsipi; and Efrat Kalderon (2011). Older adults: Are they ready to adopt health-related ICT? International Journal of Medical Informatics, vol. 82, no.11, pp. 209-231.

Katz, Stephen (2013). Active and Successful Aging. Lifestyle as a Gerontological Idea. Recherches sociologiques et anthropologiques, vol. 44, no. 1, pp. 33-49.

Formal law regulation (2011). Regulations for the allocation of care housing in, Oslo municipality, Oslo https://lovdata.no/dokument/OV/forskrift/2010-12-15-1896\#KAPITTEL_2. Accessed 5 April 2016.

Mao, Hui-Fen; Ling-Hui Chang; Grace Yao; Wan-Yin Chen; and Wen-Hi W. Huang (2015). Indicators of perceived useful dementia care assistive technology: Caregivers' perspectives. Geriatr Gerontol Int, vol. 15, pp. 1049-1057.

Milligan, Christine; Celia Roberts; and Maggie Mort (2011). Telecare and older people: who cares where? Social Science \& Medicine, vol. 72, no.3, pp. 347-354.

Ministry of education and research (2013). Meld. St. 29 (2012 - 2013) Tomorrows healthcare. Ministry of Health and Care Services, Print: Oslo.

NAKU (2017). The care staircase. http://naku.no/kunnskapsbanken/omsorgstrappa. Accessed 5 April 2017.

Norwegian Institute of Public Health (2015). These are the death cause in Norway and the rest of the world. Findings from the international burden of disease project. http://www.fhi.no/eway/default.aspx?pid=239\&trg=Area_7064\&Main_6157=6261:0:25,9086\&M ainContent_6261=7064:0:25,9086\&Area_7064=6178:113361::0:7065:1:::0:0. Accessed 4 October 2015 .

NOU (2011). Ministry of Education and Research (2011), NOU 2011:11 - Innovation in care, Ministry of Health and Care Services, Print: Oslo.

NOU (2013). Ministry of Education and Research (2013). Meld. St. 29 (2012-2013) Tomorrows healthcare. Ministry of Health and Care Services, Print: Oslo. 
NRK (2015). Thousands of elders die after a hip fracture. https://www.nrk.no/livsstil/tusenvis-doretter-hoftebrudd-1.12176988. Accessed 18 October 2015.

Oslo University Hospital (OUS) (2015). Method book for specialists in internal medicine: Delirium, acute confusion. http://www.helsebiblioteket.no/retningslinjer/metodebok/geriatri/delirium-akuttforvirring. Accessed 10 October 2015.

Petrakou, Alexandra (2007). Exploring cooperation through a binder: A context for IT tools in elderly care at home. In L. J. Bannon et al. (eds.): ECSCW'07. Proceedings of the Tenth European Conference on Computer Supported Cooperative Work, Limerick, Ireland, 24-28 September 2005. London: Springer, pp. 271-290.

Piras, Enrico M.; and Alberto Zanutto (2010). Prescriptions, X-rays and Grocery Lists. Designing a Personal Health Record to Support (The Invisible Work Of) Health Information Management in the Household. Computer Supported Cooperative Work (CSCW), vol. 19, no. 6, December 2010, pp. 585-613.

Procter, Rob; Trisha Greenhalgh; Joe Wherton; Paul Sugarhood; Mark Rouncefield; and Sue Hinder (2014). The Day-to-Day Co-Production of Ageing in Place. Computer Supported Cooperative Work $(C S C W)$, vol. 23, pp. 245-267.

Rowe, John W.; and Robert L. Kahn (1997). Successful aging. The Gerontologist, vol. 37, no. 4, pp. 433-440. doi: 10.1093/geront/37.4.433.

Schorch, Marèn; Lin Wan; David W. Randall; and Volver Wulf (2016). Designing for Those who are Overlooked: Insider Perspectives on Care Practices and Cooperative Work of Elderly Informal Caregivers. In G. Fitzpatrick et al. (eds.): CSCW'16. Proceedings of the 19th ACM Conference on Computer-Supported Cooperative Work \& Social Computing San Francisco, California, USA, 27 February-02 March, 2016. New York: ACM, pp. 787-799.

Senior report, Oslo Municipality (2014). Senior report for Oslo municipality. http://www.sak.oslo.kommune.no/dok/Vedlegg\%5C2014_05\%5C1049733_1_1.PDF. Accessed 5 October 2014.

Siek, Katie A.; Danish U. Khan; Stephen E. Ross; Leah M. Haverhals; Jane Meyers; and Steven R. Cali (2011). Designing a personal health application for older adults to manage medications: a comprehensive case study. Journal of medical systems, vol. 35, no. 5, pp. 1099-1112.

Statistic Norway (2013). Elderly people use of healthcare services. https://www.ssb.no/helse/artiklerog-publikasjoner/eldres-bruk-av-helse-og-omsorgstjenester. Accessed 7 November 2015.

Strauss, Anselm L.; Shizuko Fagerhaugh; Barbara Suczek; and Carolyn Wiener (1985) Social Organization of Medical work, Chicago: University of Chicago Press (1985).

Wagner, Ina (1993). A web of fuzzy problems: confronting the ethical issues. Communications of the $A C M$, vol. 36 , no. 6 , pp. $94-101$.

Younger, Janet B. (1991). A theory of mastery. Advances in Nursing Science, vol. 14, no. 1, pp. 76-89. 
Woll, Anita (2013). Aging in Place: Dealing with Breakdown of Welfare Technology. In J. MolkaDanielsen et al. (eds.): IRIS 13. Selected Papers of the Information Systems Research Seminar in Scandinavia, Gran, Norway,11-14 August 2013. Oslo: Akademika forlag, vol. 4 (2013), pp. 77- 90.

Woll, Anita (2016a). Introduction of telecare mediated home care services pushes forward a redelegation of the cooperative care work. In G. Salvendy and J. Zhou (eds.): HCI'16. Proceedings of the second International Conference on Human Aspects of IT for the Aged Population, Held as Part of HCI International 2016, Toronto, Canada, 17 - 22 July 2016. Cham: Springer International Publishing AG, vol. 9755, pp. 133-144.

Woll, Anita (2016b). Is aging the new disease? In L. Miller et al. (eds.): ACHI'16. Proceedings the 9th International Conference on Advances in Computer-Human Interactions, Venice, Italy, $24-28$ April 2016. Print: IARIA XPS Press, pp. 21-28.

Woll, Anita (2017). Use of welfare technology in elderly care. Ph.D. dissertation. University of Oslo. Oslo: Department of informatics, University of Oslo. http://urn.nb.no/URN:NBN:no-58321.

Woll, Anita; and Tone Bratteteig (2018). Activity Theory as a Framework to Analyze TechnologyMediated Elderly Care. Mind, Culture and Activity, vol. 25, no.1, pp. 6-21. 